Hans-Jürgen Rautenberg

Drei Dokumente zur Planung eines 300000 Mann-Friedensheeres aus dem Dezember 1933

\title{
Vorbemerkung
}

Die präzise Datierung rüstungspolitischer Entscheidungen und rüstungstechnischer Planziele in der Anfangsphase der Aufrüstung im Dritten Reich bereitet noch immer Schwierigkeiten ${ }^{1}$. Das gilt vor allem für die personelle Rüstung. Die Entwicklung im großen ist bekannt. Die Einbindung des rüstungspolitischen Entscheidungsprozesses in die wechselseitige Bedingtheit von außenpolitischen Rahmenbedingungen und innenpolitischem Spannungsfeld ${ }^{2}$ ist zur Genüge untersucht worden. Doch fehlen in Einzelfällen noch dokumentarische Belege ${ }^{3}$.

Diese Dokumentation soll helfen, für die Übergangsphase vom Heer der Reichswehr zum Heer der Wehrmacht mit allgemeiner Wehrpflicht - also für die Jahre 1933-1935 - anhand grundlegender Planungsdokumente einige Entwicklungskonstanten zu gewinnen.

\section{Allgemeine Aspekte}

Vielleicht hätte 1919 eine aus freien Stücken angenommene und nicht zudiktierte Begrenzung des deutschen Heeres auf 300000 oder gar auch 200000 Mann nicht jenes Trauma vom gedemütigten Deutschland entstehen lassen, dem die Sieger "die Waffen aus der Hand geschlagen hatten «. Die politischen Bestimmungen des Versailler Vertrages (VV) wären im ganzen erträglicher gewesen, wenn dem Deutschen Reich das Recht unbenommen geblieben wäre, den Rahmen seiner Rüstungen und sein Wehrsystem selbst zu bestimmen. So aber blieb das Land, das sich in einem militärisch wehrlosen Zustand befand, ein Fremdkörper inmitten einer hochgerüsteten Staatenwelt. Die Stärkung ihrer außenpolitischen Stellung im europäischen Staatengefüge, eine Politik, die von allen Staaten - einschließlich Deutschlands - betrieben wurde, lief Bestrebungen zuwider, die durch den Weltkrieg erschütterten sozialen Gefüge mit dem Ziel größerer sozialer Symmetrie zu stabilisieren.

Auch die demokratisch legitimierten deutschen Regierungen vor 1933 sahen sich gezwungen, der Konzentration der Kräfte auf die sozialen Probleme entscheidende Energiequellen zu entziehen und sie an militärisch fragwürdige, politisch aber höchst folgenreiche geheime Rüstungsprojekte zu binden. Der Höhepunkt der Weltwirtschaftskrise fiel mit den Vorbereitungen und dem Beginn der Abrüstungskonferenz zusammen; das hätte dem (soziale) Kosten sparenden Abrüstungsgedanken durchaus förderlich sein können. So aber schälte sich nach den ersten enttäuschenden Erfahrungen schon sehr bald die Alternative einer Rüstungskonvention heraus, eines völkerrechtlichen Vertrages zum Ausgleich der bestehenden Ungleichgewichte in den nationalen Rüstungen.

Seit 1926, kurz bevor die letzten Mitglieder der Internationalen Militärkontrollkommission (IMKK) Deutschland verließen, wurden im Reichswehrministerium (RWM) geheime Planungen zur materiellen und personellen Rüstung der Reichswehr begonnen. Sie erreichten im Jahre 1930 einen ersten Höhepunkt im 2. Rüstungsprogramm (1930-1934) 4 und mündeten 1932 in einen Milizplan (7. November 1932) ${ }^{5}$ zur personellenErweiterung des Heeres, das in seinem aktiven Bestand, grob gesprochen, verdoppelt werden sollte. Weniger der tatsächliche Zuwachs an militärischer Kraft war das Bemerkenswerte dieser Planungen, als der Beginn einer militärisch-politischen 
Gedankenkette, in die sich in der Folgezeit Glied um Glied kontinuierlich - und dem zunehmenden historischen Gefälle angepaßt - einfügte.

Die im folgenden dokumentierten Planungen aus dem Dezember 1933 für ein 300000 Mann-Friedensheer (Verdreifachung des Heeres) müssen in diesem Zusammenhang als ein Glied in der langen Kette von Perspektive und Realisierung angesehen werden, an deren Ende schließlich das versiebenfachte Friedensheer des Jahres 1939 stand. Von dem jeweils vorhergehenden Rüstungsplateau aus wurde schrittweise das nächsthöhere angegangen. Das Voranschreiten bestimmten bis 1935 die militärischen Führungen, ab 1935 aber Hitler als alleiniger politischer »Führer «. Zusätzlich komplizierend wirkte die Tatsache, daß die Planziele für die personelle und materielle Rüstung auf den meisten Ebenen nicht aufeinander abgestimmt waren. Man muß die Jahre 1926-1939 rüstungs- und planungshistorisch als eine Einheit betrachten, die ihre Eigengesetzlichkeit und ihre Kontinuitäten auch vor dem Hintergrund der großen politischen Zäsuren nicht verleugnen kann. Trotzdem ergibt sich für den rückschauenden Betrachter das verwirrende Bild vorzeitig verwirklichter Planziele, von Umbauruinen und Planungstrümmern, die einfach stehenblieben, zeitlicher Überschneidungen, hastig vorgezogener Teilziele und kurzfristiger Schwerpunktwechsel, ein Bild, das in seiner Gesamtheit als Abbild der politischen „Epochentendenzen « erscheint. Es fällt schwer, dahinter einen von Hitler konstruierten "Stufenplan « zu vermuten.

Um den Platz der Dezemberdokumente in der Phase der gedanklichen und realen Aufrüstung (1926-1939) zu bestimmen, erscheint es zweckmäßig, systematische Näherungswege einzuschlagen. Zunächst wird der außenpolitische Bedingungsrahmen skizziert. In engem Zusammenhang damit stehen die Planziele und Konzeptionen, die entworfen, modifiziert und realisiert wurden. Innenpolitische Faktoren beeinflußten und begrenzten ihren Umfang und die Zeit ihrer Verwirklichung. Innenpolitisch wirkten vor 1933 Hemmnisse auf die Planungen ein, die der Natur Deutschlands als eines demokratisch verfaßten Staates mit einer kontrollierenden öffentlichen Meinung entsprangen. Nach 1933 fielen diese Hemmnisse fort; an ihre Stelle trat der SA-Konflikt. Er wurde im Jahre 1934 "gelöst«. Danach war die Um- und Aufrüstung der Reichswehr/Wehrmacht im wesentlichen frei von innenpolitischen Restriktionen. Eine Inhaltsangabe der Dokumente mit einer Analyse der Planungsschwerpunkte und des vorangegangenen Entscheidungsprozesses schließen die Einführung ab.

\section{Außenpolitische Aspekte}

Am 2. Februar 1932 war in Genf die Konferenz zur Herabsetzung und Begrenzung der Rüstungen zusammengetreten. Der deutsche Standpunkt in der Abrüstungsfrage war unmittelbar aus der auf Revision des Versailler Vertrages abzielenden deutschen Außenpolitik abgeleitet. Die Frage der deutschen Gleichberechtigung hing eng damit zusammen. Die Konferenz stand ganz im Zeichen des deutsch-französischen Gegensatzes. In den formelhaft verkürzten Zielvorstellungen trafen sich beide Länder $z$ war im Wunsch nach Sicherheit in Europa, in den Wegen ihrer Verwirklichung aber gab es unüberbrückbare Meinungsunterschiede. Deutschland forderte: Sicherheit durch Abrüstung, Frankreich hingegen: erst Sicherheit dann Abrüstung.

Deutschland hatte gemäß den Bestimmungen des Versailler Vertrages auf ein Heer abgerüstet, das mausschließlich zur Aufrechterhaltung der Ordnung innerhalb des Gebietes (des deutschen Reiches) und als Grenzschutz verwandt werden « sollte. (Art. 160 VV). Deutschland hatte also abgerüstet; diese Tatsache und der Hinweis, von hochgerüsteten Nachbarn umgeben zu sein, verschafften der deutschen Verhandlungsführung einen taktischen Vorteil, der seinen Niederschlag in den Verhandlungsrichtlinien fand. "Das Ziel Deutschlands muß sein . . . sich einen Weg zu öffnen, der 
führt. Verschiebt sich bei der Abrüstung die bestehende Rüstungsrelation . . . so steigt die Sicherheit Deutschlands auf Kosten seiner Nachbarn « ${ }^{6}$.

Dieses Ziel konnte auf zwei Wegen erreicht werden: einmal durch einseitige Lossagung von allen die deutschen Rüstungen beschränkenden Bestimmungen, zum anderen im Rahmen einer Konvention, die die Rüstungsrelationen der europäischen Staaten untereinander festsetzte. Ernsthaft wurde eine deutsche Aufrüstung durch Weimarer Regierungen allerdings nur im Konnex einer Konvention ins Auge gefaßt. Nach zähen Verhandlungen erreichte die Reichsführung am 11. Dezember 1932 von Frankreich vor allem das Zugeständnis der formalen Gleichberechtigung.

Hitler übernahm nach der Machtübernahme den außenpolitischen Spielraum, den Weimarer Regierungen in der Rüstungsfrage bis dahin erreicht hatten. Nach erneutem Zusammentritt am 2. Februar 1933 konzentrierten sich die Verhandlungen auf der Abrüstungskonferenz verstärkt auf das Zustandekommen einer Konvention.

Unter dem Eindruck der innenpolitischen Vorgänge in Deutschland versuchte der britische Premierminister MacDonald mit dem Vorschlag einer Konvention, die sowohl dem französischen Sicherheitsbedürfnis als auch den deutschen Forderungen nach Verbesserung seiner Rüstung gerecht werden sollte, die Konferenz vor ihrem Zusammenbruch zu retten. Deutschland sollte über ein Heer von 200000 Mann verfügen dürfen, auf eine Luftrüstung aber weiterhin verzichten müssen. Die Konvention kam nicht zustande. Einerseits versteiften sich die französischen Sicherheitswünsche, andererseits war bald ersichtlich, daß sich das nationalsozialistische Deutschland nicht mit einer derart geringfügigen Vermehrung seiner Streitkräfte zufrieden geben würde. Allerdings wurden im Jahre 1933 auch keine nennenswerten Truppenteile für das deutsche Heer neu aufgestellt - entgegen Hitlers Ankündigung vor der Generalität am 3. Februar 1933: vordringlich sei die Beseitigung der militärischen Ohnmacht des Reiches.

Am 14. Oktober 1933 verließ Deutschland Abrüstungskonferenz und Völkerbund $(\mathrm{VB})^{7}$. Damit waren alle Versuche gescheitert, im Rahmen eines kollektiven Sicherheitssystems eine Rüstungskonvention in Europa abzuschließen.

Zweifellos war die Reichswehrführung die treibende Kraft beim Zustandekommen des Austrittsbeschlusses gewesen. Der formale Ablauf der Konsultationsverfahren und der Informationsprozesse zwischen der Delegation in Genf, dem Auswärtigen Amt (AA) und dem Reichswehrministerium in Berlin und nicht zuletzt Hitler selbst, ließen erkennen, daß diese außenpolitische Entscheidung militärpolitischer Motivation entsprang ${ }^{8}$.

Wenn Rüstung mit völkerrechtlicher Verbindlichkeit auch nicht zu erreichen war, deutete Hitler mit seinen Versuchen, bilaterale Rüstungsabsprachen einzugehen doch an, daß ein völlig vertragloser Zustand seinem taktischen Kalkül zunächst nicht entsprach.

Sofort nach dem Austritt aus dem Völkerbund steuerte er solche Gespräche auf Regierungsebene an. Am 24. Oktober empfing er den neuernannten britischen Botschafter in Berlin, Sir Eric Phipps ${ }^{9}$. Hitler forderte gesprächsweise ein "Einfrieren der Rüstungen «. Wenn die hochgerüsteten Staaten, Frankreich und Großbritannien vor allem, den jetzigen Stand ihrer Rüstungen nicht erhöhen würden, wäre Deutschland bereit, sich mit einem Heer von 300000 Mann zufriedenzugeben. Die Zahl 300000 ergab sich weniger aus rüstungstechnischen oder strategischen Ubberlegungen als vielmehr aus dem politisch-propagandistischen Kalkül, nur die Hälfte des 600000 Mann starken französischen Heeres für Deutschland als ausreichend hinzustellen. Einen Monat später regte Hitler dem französischen Botschafter gegenüber an, die Rüstungen Frankreichs und Deutschlands im Verhältnis $2: 1$ fest zu verankern ${ }^{10}$. In beiden Fällen aber handelte es sich nicht um »konkrete Vorschläge, sondern um Äußerungen, die zeigen 
sollen, in welcher Richtung wir eine Lösungsmöglichkeit sehen «, schwächte das Auswärtige Amt in einem Runderlaß an alle Botschaften und Gesandtschaften schon bald $a b^{11}$. Die politisch-diplomatische Reaktion in den westlichen Hauptstädten ${ }^{12}$ auf diese "Vorschläge " bestätigte sehr bald die deutsche Annahme, daß mit mehr als verbalem Protest nicht zu rechnen war.

Die französische Forderung, Deutschland unter eine "periode de bon conduite“ zu stellen, bevor man erneut in Rüstungsverhandlungen eintreten könnte, verdeutlichte das ganze Ausmaß der erschöpften politischen Gegenmaßnahmen. Die Forderung blieb ohne Folgen, die bilateralen Gespräche zogen sich bis in den April 1934 hin. Damit war für Hitler der Weg frei, im Memorandum zur Rüstungsfrage vom 18. Dezember $1933^{13}$ die deutschen Wünsche regierungsoffiziell zu verkünden. Der Verlauf des intensiven Notenaustausches zwischen den wichtigsten europäischen Staaten im Winter/Frühjahr 1933/34 mußte ihm noch einmal die Richtigkeit des eingeschlagenen taktischen Weges bestätigen. Ein weiterer Erfolg, die Rüstungsfrage bilateral zu regeln und sich tunlichst auf keine geschlossene Front von Verhandlungsgegnern einzulassen, war Hitler insofern beschieden, als er bis zur endgültigen Beseitigung der Militärbestimmungen des Versailler Vertrages (Rheinlandbesetzung) Zeit gewann, die Umund Aufrüstung nach und nach dem Verhandlungsgang und der internationalen Entwicklung anzupassen.

Die französische Regierung beendete mit ihrer Note vom 17. April $1934^{14}$ für den Augenblick den Rüstungsdialog und verwies als Alternative wieder auf den Versailler Vertrag, allenfalls auf eine Regelung im Rahmen kollektiver Sicherheit. Das aber bedeutete eine Wiederbelebung der Abrüstungskonferenz. Durch Sonderbeauftragte (Ribbentrop) und eine rege Reisediplomatie wurden die Rüstungsgespräche vom Sommer 1934 bis zum Frühjahr 1935 weitergeführt.

\section{Pläne und Planungskontinuitäten}

Bis zum Dezember 1933 war die tatsächliche Entwicklung der deutschen Rüstungen eher rückläufig gewesen. Entscheidungen, die angekündigt waren, blieben aus. Vorarbeiten, auf der Grundlage der Pläne vom 7. November 1932, meist organisatorischer Art, wurden zwar weiter vorangetrieben, ihnen mangelte es aber unter den veränderten politischen Verhältnissen an einer faßbaren Orientierungsgröße. Während der Abrüstungsverhandlungen des Jahres 1933 hatte die französische Delegation ständig auf die Offenlegung der deutschen personellen Rüstungspläne gedrängt, ohne sie jedoch für negotiabel erklären zu wollen. Nicht zuletzt deshalb, weil es - wenigstens auf dem personellen Sektor - keine weiterreichenden Zielvorstellungen gab als die Milizpläne vom November 1932, unterblieb eine Konkretisierung des Rüstungsprogramms. Die Pläne vom November 1932 bewegten sich ohnehin im zahlenmäßigen Rahmen des MacDonald-Planes und versprachen verhandlungstaktisch kaum einen Gewinn.

Den materiellen Rüstungsprojekten ${ }^{15}$ war in den Jahren 1932/1933 mehr Erfolg beschieden; sie ließen sich vor der Offentlichkeit des In- und Auslandes auch viel eher verschleiern als personelle Erweiterungen des vorgeschriebenen Heeresrahmens von 100000 Mann. Doch zeigte sich jetzt mit aller Deutlichkeit, daß die zeitlich vorgezogene materielle Zurüstung eben nicht auf einen mit Sicherheit zu erwartenden erweiterten Personalrahmen abgestimmt war.

Ein Dilemma der zu Zeiten der Weimarer Republik betriebenen militärischen Revisionspolitik und ihres rüstungspolitischen Korrelates bestand darin, daß personelle und materielle Rüstungsprojekte - aus Gründen eines ungleichgewichtigen politischen Reizwertes - zu keiner Zeit in einer gemeinsamen Zielgröße konvergierten. Entweder waren die materiellen Rüstungsprojekte übergreifend angelegt - in concre- 
to: auf ein Kriegsheer - oder die personellen Zieldaten zogen ihre materielle Untermauerung nach sich. Das war der Kern des Problems, das der Chef des Truppenamtes auf den Generalnenner brachte: "Für die Überführung des 300000 Mann-Friedensheeres in das Kriegsheer sind je nach dem Fortschreiten der materiellen und personellen Rüstung verschiedene Verfahren möglich. «(Dok. 1, Ziff. III)

Auf Hitlers Ankündigung vom 3. Februar 1933, den Belangen der Landesverteidigung unbedingten Vorrang einzuräumen, war zunächst nichts weiter geschehen als die Fortführung organisatorischer Vorarbeiten, die dem Wehrplan vom 7. November 1932 entsprangen. Die geringfügige Vermehrung des Heeres um ca. 15000 Mann zum 1. April 1933 fiel dabei kaum ins Gewicht ${ }^{16}$.

Hitler trat zwar in die vor seiner Machtübernahme entwickelte rüstungspolitische Programmatik und Kontinuität ein, zu bestimmten Höhepunkten einer krisenhaften Entwicklung seiner Außenpolitik jedoch (Mai-Krise; Austritt aus dem Völkerbund) griff er mit gegensteuernden Weisungen ein, sich bei der Aufrüstung "größte Zurückhaltung " ${ }^{17}$ aufzuerlegen.

Planziele, die 1932 im Reichswehrministerium entwickelt worden waren, vor allem für die Luftstreitkräfte ${ }^{18}$, wurden revidiert, Termine für ihre zeitliche Verwirklichung geändert, geplante Größenordnungen wurden sogar unterschritten. Weisungen für eine großangelegte Aufrüstung sind für das Jahr 1933 nicht nachweisbar.

Erst an der Schwelle zum Jahr 1934 schien die Zeit reif zu sein, der allgemeinen Richtungslosigkeit ein vorläufiges Ende zu setzen.

Bei seiner außerordentlichen Machtfülle, seiner quasi immediaten Stellung zu Hitler und seinen zunehmenden Eingriffen »in die Befugnisse der Heeresleitung . . . oder Rechte aus ihrem Bereich ${ }^{19}$, konnte Blomberg den Befehl zur Verdreifachung des Heeres geben, ohne daß es einer ausdrücklichen Weisung des Reichskanzlers bedurft hätte.

Gegen diese Macht- und Kompetenzfülle stand Hitlers bemerkenswerte Zurückhaltung, direkten Einfluß auf Rüstungspläne, Organisationskriegsspiele, oder den Umbau des Heeres in rein militärfachlicher Hinsicht zu nehmen ${ }^{20}$. So findet sich in den Quellen auch kein Beleg, daß Hitler dem Reichswehrminister eine Aufstellungsweisung gegeben hatte; umgekehrt aber kann davon ausgegangen werden, daß der Befehl zur Aufstellung des 300000 Mann-Heeres Hitlers stillschweigende Billigung gefunden hätte.

Im Vorfeld dieser für das Jahr 1934 bedeutsamen Entscheidung überschnitten sich die außenpolitischen Entwicklungslinien, die Hitler in der Rüstungsfrage (nach)gezeichnet hatte mit den militärfachlichen Plankurven des Wehrressorts. Beides bewegte sich während des Jahres 1933 aufeinander zu und fügte sich für den Augenblick zu einem sinnvollen Ganzen.

Die Reichswehr stand noch außerhalb des detailbesessenen, persönlichen Einflusses, wie ihn Hitler in späteren Jahren ausübte. Anders ausgedrückt: im Plan für ein 300000 Mann-Heer koinzidierten für einen historischen Moment die zu Zeiten der Republik entwickelte Militärpolitik zur Revision des Teiles V des Versailler Vertrages und eine durch militärische Mittel voranzutreibende Gesamtrevision der europäischen Nachkriegsordnung, wie sie Hitlers erklärtes Ziel war.

Um die militärische Beurteilung des Aufstellungsplanes und die Genesis der Dezember-Dokumente deutlicher hervorzuheben, erscheint es notwendig, sie in die Planziele und Konzeptionen seit 1926 einzuordnen ${ }^{21}$.

Die nachstehende Ubersicht soll noch einmal erkennen lassen, daß die Phase zwischen 1926 und 1939 als eine Einheit von Planung, Realisierung und stufenweiser Weiterführung betrachtet werden kann; in diesen 13 Jahren ist das deutsche Heer um das Siebenfache seines ursprünglichen Umfanges erweitert worden. 


\begin{tabular}{|c|c|c|c|c|}
\hline \multirow[t]{2}{*}{ Jahr } & \multicolumn{2}{|c|}{ personell } & \multirow[t]{2}{*}{ materiell } & \multirow[t]{2}{*}{ Bemerkungen } \\
\hline & Frieden & Krieg & & \\
\hline 1926 & 7 Div. & 21 Div. & $\begin{array}{l}\text { 1. Rüstungsprogramm } \\
(1928 / 32) \\
\text { Notausstattung }\end{array}$ & \\
\hline 1928 & 7 Div. & 16 Div. & Zwischenziel & $\begin{array}{l}\text { nur für } 7 \text { Div. Ausstattung } \\
\text { mit neuzeitlichem Gerät } \\
\text { und Waffen. A-Plan v. } \\
\text { 30. 6. } 1927\end{array}$ \\
\hline 1930 & 7 Div. & 21 Div. & $\begin{array}{l}\text { 2. Rüstungsprogramm } \\
(1933 / 38)\end{array}$ & \\
\hline 1931 & 7 Div. & 21 Div. & 2. Rüstungsprogramm & $\begin{array}{l}\text { geändertes } 6 \text { Wochen- } \\
\text { Notprogramm }\end{array}$ \\
\hline 1932 & $\begin{array}{l}144000 \\
\text { Mann akti- } \\
\text { ves Rahmen- } \\
\text { heer; dazu } \\
85000 \text { kurz- } \\
\text { dienende } \\
\text { E-Mann- } \\
\text { schaften }\end{array}$ & & & $\begin{array}{l}\text { Milizplan v. 7. 11. } 1932 \\
\text { Verdoppelung des } \\
\text { Friedensheeres }\end{array}$ \\
\hline 1933 & $\begin{array}{l}21 \text { Div. } \\
(1934 / 38)\end{array}$ & 63 Div. & & $\begin{array}{l}\text { Weisung vom } 18.12 .1933 . \\
\text { Verdreifachung des } \\
\text { Friedens-Heeres }\end{array}$ \\
\hline 1934 & 21 Div. & 63 Div. & $\begin{array}{l}\text { 2. Rüstungsprogramm } \\
\text { verwirklicht }\end{array}$ & Vorzeitige Verwirklichung \\
\hline 1935 & 36 Div. & 72 Div. & $\begin{array}{l}\text { Vierjahresplan } \\
\text { (1936) }\end{array}$ & $\begin{array}{l}\text { Bei Einführung der Allgem. } \\
\text { Wehrpflicht ist der Rahmen } \\
\text { von } 21 \text { Div. erreicht. } \\
\text { Verfünffachung des Heeres }\end{array}$ \\
\hline 1939 & 51 Div. & 102 Div. & & $\begin{array}{l}\text { Mobilmachung 1939; } \\
\text { Versiebenfachung des } \\
\text { Friedens-Heeres }\end{array}$ \\
\hline
\end{tabular}

IV. Der SA-Konflikt als Restriktionselement

Die bestehenden und in ihrer langfristigen Auswirkung jetzt erst offenbar werdenden Rüstungsbestimmungen des Versailler Vertrages können zusammen mit dem schwelenden SA-Konflikt als gegebene Konstanten bezeichnet werden, mit denen jede militärische Führung in ihren Planungen zunächst zu rechnen hatte. Variabel und damit die Planungen in Rhythmus und Tempo ihrer Durchführung beeinflussend, war die außenpolitische Entwicklung in Rechnung zu stellen. Eine zielsetzende Mitbestimmung hatte die Reichswehrführung spätestens mit dem Austritt aus dem Völkerbund, Mitte Oktober 1933, verloren. Das erklärt auch die Beiläufigkeit, mit der in allen drei Dokumenten auf die außenpolitische Lage Bezug genommen wird.

Diese Beiläufigkeit ist um so bemerkenswerter, als sich während des Jahres 1932 das Entscheidungszentrum in der Rüstungsfrage zunehmend vom Auswärtigen Amt zum Wehrressort verlagert hatte. Im Winter $1932 / 33$ besaß das Reichswehrministerium in 
der Rüstungspolitik faktisch ein außenpolitisches Monopol. Im Herbst 1933 war ein planungsbegrenzendes Element in Gestalt der Abrüstungskonferenz fortgefallen, ohne daß sich die militärische Führung damit von allen außenpolitischen Restriktionen frei sah.

Das zweite Restriktionselement resultierte aus dem Konflikt mit der SA, der zu Beginn des Jahres 1934 seinem Höhepunkt entgegentrieb. Die Dokumente legen davon beredtes Zeugnis ab. Zwar stimmte die Reichswehrführung mit Hitler darin überein, daß »außer der vormilitärischen Ausbildung alles bei der Reichswehr liegt «, nur schaltete die gemeinsame Auffassung noch nicht die Bestrebungen der SA aus, "eine eigene Wehrmacht zu gründen « ${ }^{22}$. Das konkurrierende Machtstreben beider Führungen beeinträchtigte vor allem die militärischen Umrüstungsarbeiten.

Die Option SA, der Hitler nach dem unterschiedlichen Urteil in der Literatur einmal »gefühlsmäßig zuneigte«, ein andermal »wachsende Abneigung entgegenbrachte, muß er schließlich als ein absolut untaugliches Mittel für seine außenpolitischen Ziele eingeschätzt haben ${ }^{23}$.

Aber solange der Konflikt zwischen den konkurrierenden Machtgruppen nicht entschieden war, kam weder die um das "Waffenträgermonopol « bangende Reichswehr zum Zuge noch Röhm mit seinen revolutionären Milizplänen. Das NS-Regime durchschritt zudem noch die Phase der Konsolidierung und erst als sich die Herrschaftsstrukturen einigermaßen verfestigt hatten, traf Hitler eine Entscheidung im Sinne der Reichswehr als der alleinigen bewaffneten Macht im Staate.

Dabei hat es nicht an Versuchen der Reichswehrführung gefehlt, ihrerseits den Konflikt zu entscheiden und zu beenden; dazu reichte ihr eigenes Gewicht aber schon nicht mehr aus.

Da sich zudem der erste Soldat der Reichswehr, General v. Blomberg, schon zu sehr auf die neuen Machthaber eingelassen hatte, waren alle diese Versuche nur aufschiebender Natur. In einer Vereinbarung zwischen SA-Führung und Reichswehrführung vom Februar 1934 zur Abgrenzung der beiderseitigen Kompetenzen in Fragen der Landesverteidigung kam die zögernde und lediglich konfliktbegrenzende Grundhaltung der Reichswehrführung besonders zum Ausdruck ${ }^{24}$. Wirklich entschieden wurde wenig, was auch die Weisungen der Heeresleitung zur Weiterführung der SAAusbildung im Grenzschutz-Ost widerspiegeln.

Der Preis für diesen fast eineinhalb Jahre währenden Zustand des Nebeneinanders zweier Kraftzentren war eine Verzögerung der Umrüstungsmaßnahmen im Jahre 1933. Erst am Ende des Jahres gelang es, allgemein richtungweisende Planungen in die Wege zu leiten.

Aber auch diese Pläne griffen ältere aus dem Jahre 1932 auf, sie waren mit Hypotheken belastet, die unter ganz anderen politischen Voraussetzungen eingegangen worden waren.

Die Pläne vom November 1932, die Reichswehrminister Schleicher gebilligt hatte, waren im ganzen doch als Notmaßnahmen einzustufen, die politisch eine Revision der Versailler Militärbestimmungen zum Ziel hatten und militärisch auf eine "Pflicht zur Notwehr « hinausliefen. In diesem Zusammenhang ist auch die weitgehende "Auslagerung “ des Reichsheeres in die Ausbildungsstätten der SA und des Grenzschutzes einzuordnen. Aber während sich unter Weimarer Vorzeichen die Ausbildung außerhalb des Reichsheeres als militärischer Versuch zur Schaffung wenigstens bedingt verwendungsfähiger Mannschaftsreserven militärisch rechtfertigen ließ, erhielt sie nach dem 30. Januar 1933 zusätzliche politische Sprengkraft, einmal als Teil der geistigen Mobilmachung, dann aber als Kärrnerdienst für die militärpolitischen Ziele der Parteiarmee. 
Frontstellung gegen die SA-Führung zur Voraussetzung. Dazu aber konnte sich General v. Blomberg schon deshalb nicht verstehen, weil eine schnelle und nachdrückliche Lösung der SA-Frage seinen Bestrebungen zuwidergelaufen wäre, Hitler als Person und als Verkörperung des Nationalsozialismus entgegenzukommen.

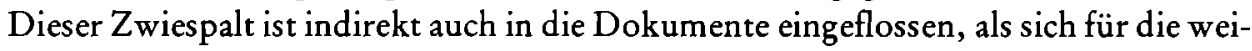
teren Planungen begrenzende Elemente und gesicherter Boden die Waage hielten. So kommt eine systematische Zusammenstellung der ungelösten Probleme, wie sie in den drei Dokumenten mehrfach genannt wurden, zu dem Ergebnis, sie in ihrer Zahl und Gewichtigkeit durchaus gegen die fixen Größen aufzuwiegen, die eine solide Ausgangslage für die praktische Aufbauarbeit begründen konnten. Zur Entscheidung standen noch an: die Regelung des Grenzschutzes, die Frage der Ubernahme von Polizeiverbänden, die Dienstzeitregelung und die Ausbildung außerhalb des Heeres. Mitte des Jahres 1933 war der überwiegende Teil der Truppenoffiziere des Reichsheeres mit der militärischen Ausbildung der SA-Mannschaft beauftragt ${ }^{25}$. Eine Konzentration der Kräfte auf die erweiterten Aufgaben des Heeresaufbaues hätte auf lange Sicht aber die SA in ihrem Anspruch »ausgetrocknet “, ein revolutionäres Volksheer zu bilden. Ohne gründliche Ausbildung unter militärfachlicher Leitung aber konnte die SA-Führung nicht den Nachweis erbringen, ein schlagkräftiges Instrument für Hitlers außenpolitische Pläne zu sein.

Geplant werden konnte mit Entscheidungen über die Verbandsgliederung, die Struktur des Offizierkorps, großräumige Dislokation der Truppenteile und verwaltungstechnische Einzelfragen, die auf gesetzgeberischer Vorarbeit aufbauen konnten. Trotz großzügiger Regelung duch im Zuge der Arbeitsbeschaffungsprogramme war auf Jahre hinaus ein Engpaß bei der angemessenen Unterbringung der Truppe zu erwarten. Praktisch präjudiziert war die Frage der Allgemeinen Wehrpflicht: „Der Ubergang vom Söldnerheer zum Heer der Allgemeinen Dienstpflicht (ist) vollzogen. « (Chef Wehramt, Dok. 3)

Die entscheidenden Unsicherheitsfaktoren, die den mittelfristig angelegten Aufstellungs- und Umbauplan vom Dezember 1933 trotz des erklärten Zieles, ihm eine »feste Begründung « zu geben, doch als ein Transitorium erscheinen ließen, resultierten aus den langfristigen Auswirkungen des Versailler Vertrages (Teil V) und dem offenen Konflikt mit der SA.

\section{Inhalt und Planungsschwerpunkte}

Die Denkschrift des Truppenamtes (T. A.) vom 14. Dezember 1933 (Dok. 1), der Befehl für den "Umbau des Heeres « vom 18. Dezember 1933 (Dok. 2) und die sich daran unmittelbar anschließende Besprechung im Reichswehrministerium am 20. und 21. Dezember 1933 (Dok. 3) bestimmten den personellen Um- und Aufbau des Heeres in den beiden darauffolgenden Jahren entscheidend mit.

Alle drei Dokumente beziehen sich auf die Aufstellung eines 300000 Mann-Friedensheeres über einen Zeitraum von vier Jahren hinweg. Die einzuleitenden Maßnahmen sollten von "Anfang an den Charakter einer festen Begründung « tragen ${ }^{26}$, das Improvisieren, wie es seit 1926 etwa betrieben wurde, schien vorbei zu sein.

Der militärstrategische Kern der Dokumente läßt sich auf drei Hauptziele ${ }^{\mathbf{2 7}}$ reduzieren:

1. Aufbau eines Friedensheeres als Grundlage für das Kriegsheer

2. Fähigkeit zur Führung eines Mehrfronten-Verteidigungskrieges

3. Beseitigung der Wehrlosigkeit durch Schaffung einer Risikoschwelle für potentielle Interventionsmächte ${ }^{28}$. 
Heeres und rascher Aufbau im Sinne der drei Hauptziele schlossen sich als gleichgewichtige Ziele aus.

Der Gedanke, mit der Aufstellung eines 300000 Mann-Heeres dem Reich die Bündnisfähigkeit zu verschaffen, tauchte nicht mehr auf ${ }^{29}$. Die wenigen Bezüge auf die auBenpolitische Konstellation und der gänzliche Verzicht, mögliche zu erwartende auBenpolitische Folgeprobleme analytisch in die Planung einzubeziehen, lassen den Schluß zu, daß der Reichswehrführung und dem Chef des Truppenamtes ein militärfachliches Aufbauprogramm vorschwebte, weniger ein "außenpolitisch fundiertes und abgesichertes Militärkonzept «" ${ }^{30}$.

Breiten Raum nehmen Probleme der Personalgewinnung, der Ausbildung und Schaffung personeller Reserven, der Personalabgaben an die im Aufbau befindliche Luftwaffe, der Unterbringung der Truppe, ihrer dienstrechtlichen Versorgung und das zentrale Aufbauproblem ein: die Struktur des erweiterten Offizierkorps.

Gliederung und Dislokation der Großverbände und der Kommandobehörden werden in der Weise bestimmt, daß die Komposition des Heeres durch die Mitte Mai 1934 einsetzenden Tempobeschleunigungen im Aufbau nicht mehr wesentlich verändert zu werden brauchten.

Das deutsche Heer hätte bei verwirklichter Planung am 1. April 1938 zu ca. 40\% (114000) aus Zeit- und Berufssoldaten und zu ca. 60\% (186000) aus Dienstpflichtigen bestanden.

Auffällig ist, daß der Grundtypus des Großverbandes, der im Krieg die Hauptlast des Kampfes zu tragen hatte - die Infanterie-Division - in seinen Elementen vorkonzipiert war. Für die motorisierten und gepanzerten Verbände begann die Konzeptionsphase erst.

Die Verdreifachung des Heeres sollte in enger Anlehnung an die sieben Wehrkreise erfolgen. Jeder Wehrkreis hatte nach seiner Drittelung in Wehrgaue jeweils drei Divisionen aufzustellen. Dislokationsschwerpunkte - entsprechend der strategischen Konzeption eines Mehrfrontenkrieges - sind nicht zu erkennen. Die Dislokation orientierte sich zunächst an der Bevölkerungsdichte. Die entmilitarisierte Zone blieb ausgespart, wenn auch Grenzsicherungsmaßnahmen entlang der Rheinlinie und organisatorische Vorbereitungen innerhalb der Zone die politischen und militärischen Bestimmungen des Versailler Vertrages vielfach schon übersprangen ${ }^{31}$.

\section{Entscheidungsprozesse}

Am 17. Oktober 1933 beauftragte der Reichswehrminister den neuernannten Chef des Truppenamtes, General Beck, mit der Abhaltung eines Kriegsspieles, dessen Aufgabe es sein sollte, Fragen der Spitzengliederung für den Kriegsfall sowie das Zusammenwirken der drei Wehrmachtsteile zu untersuchen ${ }^{32}$. Kriegsspiele dieser Art hatten Tradition, sie reichten bis in das Jahr 1926 zurück. Anfang Dezember gab die Organisationsabteilung (T2) einen Entwurf für die endgültige Regelung der »Befugnisse der obersten politischen und militärischen Führung in Krieg und Frieden ${ }^{\mathbf{3 3}}$ in den Mitprüfungsgang des Wehrressorts. Die Ergebnisse dieser Studie und die sich über die nächsten Monate hinziehende Ressortdebatte standen in fortdauerndem Zusammenhang mit Uberlegungen, wie sie schon in der Weimarer Republik angestellt worden waren.

So hatte die Organisationsabteilung (T2) in einem Entwurf zur Kriegsspitzengliederung vom 12. Dezember $1929^{34}$ gefordert, daß der oberste militärische Führer, der "Feldherr«, "Chef der Wehrmacht « oder "Generalissimus « über sämtliche militärischen Kräfte die "unbeschränkte Befehlsgewalt « besitzen müsse. 
Truppenamtes über die Organisation des Reichswehrministeriums hieß es lapidar: der Reichswehrminister hat sich zum Chef der Wehrmacht gemacht ${ }^{35}$.

Der an sich nicht neue Gedanke, daß die militärischen Kompetenzen scharf zusammengefaßt einer einzigen Person zuzuordnen seien, diese aber gleichberechtigt dem Reichskanzler als dem politisch allein Verantwortlichen zur Seite zu stellen war, erhielt unter den veränderten Voraussetzungen des Jahres 1933 eine besondere Beschaffenheit.

An der Reichswehrspitze hatte beginnend mit dem Tage der Machtübernahme Hitlers ein Sammlungsprozeß der politischen $u$ nd militärischen Kompetenzen stattgefunden, der im Ergebnis der nächsten Jahre darauf hinauslief, diese konzentrierte Macht sukzessive an die politische Gesamtführung, also Hitler und die Partei, auszuliefern. Auch in diesem Zusammenhang war zu beobachten, daß Plandaten und Organisationsziele aus der Weimarer Zeit ihres fortwährenden Kontextes beraubt wurden und in ganz anders geartete politische und militärische Konzeptionen eingefügt wurden. Dieser Problematik ist sich das Truppenamt unter Führung von General Beck von Anfang an bewußt gewesen. Die ausführlich begründeten Widerstände ${ }^{36}$ gegen eine übermäßige Konzentration von Befugnissen an der Spitze der Reichswehr, wie auch die eindringliche Warnung vor einer vorschnellen Verwirklichung des auf vier Jahre ausgedehnten Aufbauplanes - bereits im Jahre 1934 - sind weit eher politischer Natur als militärische Bedenken gewesen.

A hnlich wie es nicht gelang, die Spitzengliederung nach politischen und militärischen Erfordernissen praktikabel zu harmonisieren, konnten personelle und materielle Rüstung in kein ausgewogenes Verhältnis gebracht werden.

Dem Befehl zur Aufstellung eines 300000 Mann-Heeres ging ein wesentlich kürzerer interner Entscheidungsprozeß voraus. Am 21. November 1933 verfügte der Chef des Truppenamtes die "Durchführung [von] Vorhaben für die Weiterentwicklung des Heeres « im Jahre $1934^{37}$. Die vom Reichswehrminister genehmigten Aufstellungen waren in Umfang und Struktur dem Organisationsvorschlag für den Umbau des Friedensheeres vom 7. November 1932 entnommen, den der Chef der Heeresleitung, General v. Hammerstein-Equord, als verbindliche Leitlinie gebilligt und in Kraft gesetzt hatte ${ }^{38}$.

Die Verfügung General Becks war zunächst mit einem Innenverteiler ausgezeichnet worden und wurde nur den Ämtern gleicher Ebene zugeleitet. Neun Tage später, am 30. November $1933^{39}$, verfügte die Organisationsabteilung (T2) mit einem erweiterten Außenverteiler den Umbauplan für das Jahr 1934 an die Kommandobehörden und die Truppe.

Anfang Dezember erarbeitete die Organisationsabteilung im Truppenamt unter Leitung von Oberstleutnant v. Sodenstern eine "Denkschrift über den Aufbau des künftigen Friedensheeres ${ }^{\mathbf{4 0}}$. Sie hatte in ihren Grundgedanken bereits die Billigung des Reichswehrministers gefunden und sollte den weiteren Arbeiten als Grundlage dienen. General Beck übersandte die Denkschrift in 25 Exemplaren und mit einem erweiterten Innenverteiler den Ämtern des Ministeriums, der Marineleitung und dem Luftfahrtministerium zur Kenntnisnahme. Zur Mitprüfung oder Stellungnahme forderte er in dem Anschreiben nicht auf.

Der Hinweis auf die Billigung durch den Minister schien zu genügen. Aber auch im Truppenamt selbst ließ sich eine Mitprüfung oder Beteiligung der Operationsabteilung(T1), der Abteilung Fremde Heere(T3) oder der Ausbildungsabteilung (T4) nicht nachweisen.

Die Verdreifachung des deutschen Heeres scheint ein reines Organisationsproblem gewesen zu sein. 
berg (RWM), Beck (T. A.), Sodenstern (T2). Offensichtlich ist auch General v. Hammerstein, nominell noch Chef der Heeresleitung, nicht in den Gang der Arbeiten eingeschaltet worden. Im Vergleich zu der parallel dazu laufenden intensiven Ressortdiskussion über die Spitzengliederung, in der alle Ämter und die wichtigsten Abteilungen ausführlich zu Wort kamen und ihre Standpunkte schriftlich niederlegten, ist die Schnelligkeit, mit der diese Richtung und Ziel setzende Denkschrift erarbeitet wurde, ungewöhnlich zu nennen. Eine stichhaltige Erklärung für diesen Vorgang zu finden, fällt angesichts der Quellenlage ${ }^{41}$ schwer. Der Wehrplan vom November 1932 war sicherlich herangezogen worden. In wichtigen Punkten, so in der Dislokation der Truppe, hatte man zweifellos Vorarbeiten zur Hand. Die Aufstellung der Wehrgauleitungen, aus denen Divisionskommandos gebildet wurden, befand sich in der praktischen Durchführung ${ }^{42}$. Die Wehrgauleitungen sollten zwar ursprünglich die Aufstellungsräume für das 21 Divisionen-A-Heer vorbereiten, aber es war ein relativ leichtes, sie auch dem künftigen Friedensheer zugrunde zu legen.

Uber die Neugliederung der Ersatzorganisation für die Wehrmacht im Frieden ${ }^{43}$ war bereits im April 1933 Weisung ergangen; ebenso konnte auf verwaltungstechnische und gesetzgeberische Vorarbeiten zurückgegriffen werden. Der Rahmen des neuen Friedensheeres war gedanklich bereits vorgeprägt, Denkschrift und Aufstellungsweisung wiesen nur noch die Richtung, wie das Heer in diesen Rahmen hineinwachsen sollte.

So stand die Weisung vom 18. Dezember 1933 (Dok. 2) ganz im Zeichen einer "Erweiterung « der bisherigen Planungen und eines beschleunigten Aufbaues des Heeres. Der Umbauplan vom 30. November 1933 wurde außer Kraft gesetzt; er war zu vernichten. Auf der Weisung vom 18. Dezember 1933 ist ein entsprechender Vernichtungsvermerk nachweisbar. Es war derselbe Tag, an dem die Reichsregierung ihr Memorandum zur Rüstungsfrage veröffentlichte und die Forderung nach einem 300000 Mann-Heer politisch begründete ${ }^{44}$.

Zwei Tage später, am 20. und 21. Dezember, fand im Reichswehrministerium inBerlin eine Besprechung statt, an der aller Wahrscheinlichkeit nach die Spitzen der Reichswehr und die Truppenbefehlshaber teilgenommen haben ${ }^{45}$. Die Niederschrift dieser "Befehlshaberbesprechung « wurde von einem unbekannten Offizier des Wehrkreises (WK) VII (München) in fünf Exemplaren gefertigt und war nur für den Stab des Befehlshabers bestimmt. Es handelte sich allem Anschein nach nicht um eine nachträgliche Aufzeichnung anhand von Notizen oder Mitschriften der Besprechung, sondern um eine Bearbeitung eines offiziellen Protokolls, das in Berlin zur Verfügung gestellt wurde. Hinweise auf spezifische Organisationsprobleme des Wehrkreises VII ${ }^{46} \mathrm{deu}-$ ten darauf hin. Die Aufzeichnung gliedert sich in fünf Teile: der Reichswehrminister, der Chef des Truppenamtes, der Chef des Personalamtes, der Chef des Wehramtes und sein Chef der Allgemeinen Abteilung sowie der Chef der Ausbildungsabteilung (T4) trugen vor.

Während General Beck und General v. Blomberg am ersten Tage die Ziele im großen absteckten, waren die Vorträge der Ämterchefs am zweiten Tage auf Einzelheiten der Durchführung ausgerichtet. Unabhängig von der Besprechung waren bereits Durchführungsbestimmungen erlassen worden. Unter Bezug auf die Plandaten in der Weisung vom 18. Dezember 1933 ordnete der Chef des Wehramtes am 20. Dezember ${ }^{47}$ Bestimmungen für die Gewinnung des Ersatzbedarfes des Heeres im Jahre 1934 an. Im Zeichen einer auffälligen Eile waren auch Richtlinien für die Werbung und Annahme der Freiwilligen erlassen worden.

Innerhalb von nur drei Wochen, zwischen dem 30. November und dem 21. Dezember 1933, war befohlen worden, in einer Denkschrift den Rahmen des künftigen Friedensheeres festzulegen. Bisherige Planungen waren außer Kraft gesetzt, eine neue Pla- 
nung verbindlich erklärt und Kommandobehörden und Truppenführer über die Absichten der Führung unterrichtet worden. Gleichzeitig war der Aufbau des 300000 Mann-Heeres diplomatisch vorbereitet und als bedingte deutsche Rüstungsforderung in den weiteren Gang der bilateralen und multilateralen Rüstungsverhandlungen eingebracht worden.

Die Dezemberentscheidungen lösten eine Flut von Organisationsbefehlen, hastig vorangetriebenen Neuaufstellungen, Zellteilungen vorhandener Truppenteile, Abkürzung von Ausbildungsgängen und Neueinstellungen aus, die das Heer der Reichswehr in seinen Grundfesten erschütterten ${ }^{48}$.

Die ersehnte Ruhe einer Aufbauzeit von vier Jahren trat nicht ein. Im Mai 1934 schlug das Allgemeine Heeresamt (AHA), das schon vorher der organisationstechnische Motor der beschleunigten Aufstellung gewesen war, vor, den Aufbau des neuen Friedensheeres bereits am 1. Oktober 1934 abzuschließen ${ }^{49}$.

Oberst Fromm dürfte dabei nicht ohne das Einverständnis des Reichswehrministers gehandelt haben. Proteste der Heeresleitung und des Truppenamtes blieben nicht aus ${ }^{50}$. Schon im Januar 1934 hatte die Heeresleitung zu bedenken gegeben, daß »der beabsichtigte rasche Umbau des Heeres nur denkbar (sei) wenn der innere Wert und die Leistungen des 100000 Mann-Heeres sich auf der Höhe zeigen wie bisher " ${ }^{51}$. General Beck protestierte unmittelbar nach Bekanntwerden der Pläne noch schärfer. Sein Schriftsatz vom 20. Mai 1934 war nicht nur eine militärische Gegenargumentation, sondern eine politische Absage an die Methoden des Heeresaufbaues. Die beabsichtigten Maßnahmen förderten die Kriegsgefahr, sie seien außenpolitisch nur gerechtfertigt, wenn man glaube, an einem bewaffneten Konflikt doch nicht vorbeizukommen. Das Ganze sei nicht mehr der "Aufbau eines Friedensheeres «, sondern eine "Mobilmachung «.

Wahrscheinlich schlugen bei der Reichswehrführung die Warnungen vor einem irreparablen Qualitätsverlust des Heeres durch und nicht die politisch motivierten Bedenken, denn am 1. Oktober 1934 standen gerade 240000 Mann unter den Fahnen, d.h. das Heer hatte sich seit dem 1. April 1933 gerade verdoppelt. Mit der Wiedereinführung der Allgemeinen Wehrpflicht am 16. März 1935 war das Heer aus dem Planungsrahmen vom Dezember 1933 wieder herausgewachsen. Die neue Zielgröße war ein 36 Divisionen-Heer. Damit wurde auch das eigentliche Ziel Hitlers, ein schlagkräftiges, offensivfähiges Kriegsheer, zunehmend greifbarer. Die Inkubationszeit der Aufrüstung, die mit dem Verlegenheitsbegriff „Umrüstung “ bezeichnet wurde, war vorüber. 
1. Denkschrift des Truppenamtes in der Heeresleitung vom 14. 12. 1933 über den Aufbau des künftigen Friedensheeres ${ }^{52}$

BA-MA RH $15 / 34$.

Anliegend geht den im Verteiler genannten Stellen eine Denkschrift über den Aufbau des neuen Friedensheeres zu. Die Denkschrift hat in den Grundgedanken die Billigung des Herrn Ministers gefunden und soll als Grundlage für die weiteren Vorarbeiten dienen.

I. A.

Beck

Aufbau des künftigen Friedensheeres.

I.

Bei der Ermittlung der Kopfstärke des für den nächsten Zeitabschnitt anzustrebenden Friedensheeres ist davon auszugehen, dass das aus ihm zu entwickelnde Kriegsheer einen Verteidigungskrieg nach mehreren Fronten ${ }^{53}$ mit einiger Aussicht auf Erfolg aufnehmen kann. Weiterzielende Forderungen lassen sich zunächst weder organisatorisch ${ }^{54}$ noch rüstungsmässig ${ }^{55}$ verwirklichen. Als geringst zulässige Stärke des Kriegsheeres sind in Anbetracht der zu verteidigenden Grenzen 33 Felddivisionen und 30 Divisionen ${ }^{56}$ des Besatzungsheeres (Landwehr-Divisionen) anzusehen ${ }^{57}$.

Die Denkschrift beschränkt sich auf die personelle Seite der Heeresentwicklung. Der entsprechend dem Heeresausbau notwendige Aufbau der Kriegsrüstung ist bei entsprechendem Einsatz an Mitteln ${ }^{58}$ in wenigen Jahren durchzuführen. Von ihm hängt es ab, wann die Vervielfachung des Friedensheeres voll erreicht werden kann.

Neben den Divisionen des Feld- und Besatzungsheeres, deren Gliederung die Anlage 1 und $2^{59}$ enthält, sind $3 \mathrm{Kav}$. Divisionen (Gliederung siehe Anlage 3$)^{60}, 1$ selbst. Reiter-Brigade, 1 leichte Division (mot) (Gliederung siehe Anlage 4) ${ }^{61}, 1$ Panzerverband (Gliederung siehe Anlage 5) ${ }^{62}$ und die erforderlichen Heeres-, Armee- und Korpstruppen vorgesehen. Die für das Kriegsheer notwendigen Luftstreitkräfte (Flieger) ${ }^{63}$ sind nicht berücksichtigt.

Als Grundlage für die Aufstellung des Kriegsheeres ist ein 21 Divisionen-300000 Mann-Friedensheer mit einjähriger aktiver Dienstpflicht für die Masse der Soldaten in Aussicht genommen.

Die Einstellung zum 1.4. und 1. 7. 34 soll noch auf der Grundlage freiwilliger Meldung erfolgen. Ab 1 . Oktober 34 ist eine allgemeine Dienstpflicht vorzusehen ${ }^{64}$.

Die Dienstzeit soll für etwa $2 / 3$ der Stärken der einzelnen Einheiten 1 Jahr betragen, der Rest dient 2 oder 3 bezw. 12 Jahre. Das Verhältnis zwischen 2-jährig und 12-jährig Dienenden soll $1: 1$ betragen, bei 3-jähriger Dienstzeit 2:1. Ob von der 2-jährigen Dienstzeit zu Gunsten der 3-jährigen Dienstzeit ganz allgemein abzusehen ist, bedarf noch der Entscheidung ${ }^{65}$. Bei den bestehenden Grz.Sch.A.Batlnen ${ }^{66}$ läuft die 3-monatige Ausbildung vorläufig weiter. Ob die weiteren als Grz.Sch.A.Batlne. vorgesehenen 18 Batlne. ebenfalls mit 3-monatiger oder 1-jähriger Dienstverpflichtung auszubilden haben, bedarf noch der Entscheidung ${ }^{67}$.

Unsere militärpolitische Lage verlangt rasche Beseitigung des Zustandes völliger Wehrlosigkeit $^{68}$. Der Angriff muss für unsere Nachbarn zum Risiko werden ${ }^{69}$. Es ist unverkennbar, dass somit für die nächsten Jahre - neben der Vermehrung der Friedensstämme - die Bereitstellung ausgebildeter Mannschaften für das Kriegsheer im Vordergrunde steht. Es kommt daher darauf an, das neue Friedensheer möglichst rasch, aber doch noch auf gesunder Grundlage ${ }^{70}$ aufzubauen und dabei jede Möglichkeit zur Bildung personeller Reserven zu nützen. Der Herr Minister hat den Aufbau eines 21-Divisionen-Heeres ${ }^{71}$ mit den dafür notwendigen Korpstruppen pp. auf der allgemeinen Grundlage der bisherigen Wehrgaue genehmigt und angeordnet, dass dieses Ziel in 4 Jahren anzustreben ist.

Einen Vorschlag für den Aufbau in 4 Jahren enthält Anlage 6 ${ }^{72}$. Uber Gliederung des 21-Divisionen-Heeres siehe Anlage 7, über die Stärken Anlage $8^{73}$. 
3 Aufbaujahre beizubehalten. Verringerung auf die bisherigen Stärken ist im letzten Jahre notwendig.

Einen Vorschlag für die Dislozierung des 21-Divisionen-Heeres im Grossen enthält Anlage $9^{74}$. Er ist - soweit die militärpolitische Lage es zulässt - unter Berücksichtigung der Bevölkerungsdichte erfolgt.

Die leichte Division soll ihre Standorte in Thüringen, der Panzerverband in Brandenburg und Thüringen erhalten.

II.

Zusammensetzung des 300000 Mann-Heeres und Dienstzeiten ${ }^{75}$.

a) Offiziere 7\% der Gesamtstärke 21000

b) Längerdienende $33 \% \quad 93000$ davon $1 / 312$ Jahre 31000

$2 / 33$ Jahre 62000

c) $1 \mathrm{Jahr}$ dienende Dienstpflichtige

186000

300000

Einen Vorschlag für die Einteilung der allgemeinen Wehrpflicht und die Wiederholungsübungen enthalten Anlage 10 und $11^{76}$.

Eine Abstufung der Dienstzeit der Dienstpflichtigen nach Waffengattungen - Ausnahme Funk-, Pzkw.- und Kpfw.-Truppe ${ }^{77}$ - erscheint nicht notwendig. Sie wäre auch vom organisatorischen Gesichtspunkt aus höchst unerwünscht.

Unter den vorgenannten Voraussetzungen fallen jährlich an personellen Reserven an ${ }^{78}$ :

a) 12 Jahre dienende Kapitulanten $\quad 2583$

b) 3 Jahre dienende Kapitulanten 20667

c) $1 \mathrm{Jahr}$ dienende Dienstpflichtige 186000

209250

Schwierig gestaltet sich die Sicherstellung des Offizierbedarfs, der $7 \%$ der Gesamtstärke = 21000 Offiziere beträgt. Aushilfen werden aber auch hier möglich sein, sodass der Ausbau des Heeres daran nicht zu scheitern braucht.

Aus der Bereitschaftspolizei und aus ehemaligen Offizieren können noch etwa 2000 Offiziere $^{79}$ gewonnen werden. Der dann noch bestehende Fehlbedarf wird sich bei 2-jähriger Ausbildungszeit auf 4-5 Kriegsschulen in 6-8 Jahren heranbilden lassen. In der Aufbauzeit muss unter Beschränkung auf etwa $3 \%$ der Gesamtstärke ${ }^{\mathbf{B}}$ auch auf bewährte ältere Unteroffiziere zurückgegriffen werden, die auf 18 Dienstjahre kommen können. Nach Leistung und Persönlichkeit besonders geeignete Unteroffiziere müssen zum Offizier befördert werden können ${ }^{81}$. Der Bedarf an Längerdienenden steht aus den Einheiten des jetzigen Heeres reichlich zur Verfügung, zumal auch geeignete Kräfte aus der Bereitschaftspolizei übernommen werden können.

Mit Bildung des 300000 Mann-Heeres erscheint die Auflösung der Bereitschaftspolizei ${ }^{\text {B2 }}$ mit Ausnahme der Landes-Polizei-Inspektionen Düsseldorf und Frankfurt a/M. sowie der Reichszwischenbefehlsstelle Stuttgart schon deshalb geboten, weil damit weiterer Unterbringungsraum gewonnen und ein Teil des Offizierbedarfs gedeckt werden könnte. Vor allem aber sollte im neuen Reich nur das Heer als alleiniger Waffenträger ${ }^{83}$ und höchstes Machtmittel der Staatsgewalt bestehen.

III.

Für die Uberführung des 300000 Mann-Friedensheeres in das Kriegsheer sind je nach dem Fortschreiten der materiellen und personellen Rüstung verschiedene Verfahren möglich. Für das erste erscheint es nach erfolgtem Aufbau des 21-Divisionen-Heeres unter Berücksichtigung der Leistungsfähigkeit unserer materiellen Rüstung ${ }^{84}$ ausreichend, dass sich die Divisionen im Reichsinnern ${ }^{85}$ (9 Inf. Divisionen) und die Divisionen in Ostpreussen verdoppeln und ausserdem je 1 Landwehr-Division aufstellen, während die Divisionen an der Ost- und Westgrenze 
des Reiches ( 9 Divisionen) ${ }^{86}$ Felddivisionen bleiben und je 2 Landwehr-Divisionen aufstellen (siehe Vorschlag für Dislozierung Anlage 9). Notfalls müssen die Grenzdivisionen ohne jede Auffüllung oder sonstige besondere Mobilmachungsvorbereitung die erste Verteidigung bedrohter Grenzabschnitte übernehmen können.

Während der Aufbauzeit des neuen Friedensheeres muss der Grenzschutz an der Ost- und Südostgrenze des Reiches in der bisherigen Gliederung und Organisation ${ }^{87}$ aufrecht erhalten bleiben. Im Westen ${ }^{88}$ muss die erste Verteidigung des Rheins und des Schwarzwaldes durch die Polizeikräfte der Landesinspektionen Düsseldorf, Frankfurt a/M., sowie der Reichszwischenbefehlsstelle Stuttgart erfolgen ${ }^{89}$.

Anlage 8

Stärke für ein 21-Divisionen-Heer - 300000 Mann.

21 Inf.Divisionen zu je 10200 Mann

8 Korps-Kommandos mit Korpstruppen

214200 Mann

(Für das 8. Korps-Kommando sind eigene Korpstruppen

48627 Mann im Frieden nicht vorgesehen)

3 Reiter-Divisionen zu 4 Regtern.

1 selbst.Reit.Brigade zu 2 Regtern.

1 Kav.Korps. Kdo. mit Korpstruppen

4 Reiter-Regter, für A.A. Div.

(ohne Flak und

A. A. mot)

20437 Mann

1 leichte Division (mot) (ohne Flak und A.A. mot)

4207 Mann 5089 Mann 7440 Mann

Schulen und sonstige Heereseinrichtungen

300000 Mann

Dieser Berechnung sind im allgemeinen die bisherigen Reichsheerstärken zu Grunde gelegt.

Friedensbedarf an Korps-, Armee- und Heerestruppen für ein 21-Divisionen-Heer - 300000 Mann.

Gesamtbedarf

Personeller

Gesamtbedarf rd.

\begin{tabular}{lr}
\hline 7 Art.Regts.Stäbe & 1000 \\
14 schw.Art.Abt. zu 3 Battr. & 5740 \\
7 Beob.Abt. & 3360 \\
3 Nebel-Abt. & 1620 \\
16*) Flak.Abt. & 12000 \\
3 Fla.M.G.Batl. & 2250 \\
6 Kpfw.Batl. zu 3 leichten u. 1 mittl. Komp.**) & 6480 \\
7 7) A.A. (mot) & 5670 \\
7 Pi.Batl. (mot) & 3507 \\
7 Nachr.Abt. (mot) & 3150
\end{tabular}

Zusammen: $\quad 44777$

Ausserdem:

10 Flak.Ausb.Abt. für R.L.Schutz zu je $270 \quad 2700$

5 Fla.M.G.Ausb.Batl. für R.L.Sch. zu je $230 \quad 1150$

Anmerkung:

Insgesamt: $\quad 48627$ 
2. Weisung des Chefs der Heeresleitung vom 18. 12. 1933 über den beschleunigten Umbau des Heeres ${ }^{90}$.

$B A-M A$ RH $15 / 34$.

1. In Erweiterung der bisherigen Planungen ${ }^{91}$ für den Heeresumbau ist beabsichtigt, den Aufbau unseres Heeres zu beschleunigen. Ziel ist die Schaffung eines 21-Divisionen-Heeres mit entsprechenden Armee- und Korpstruppen gem. Anlage $1{ }^{92}$.

Der mit Chef H.L. T.A.Nr. 359/33 g. Kdos. T 2 II vom 30.11. 33 ergangene Umbauplan tritt ausser $\mathrm{Kraft}$ und ist zu vernichten ${ }^{93}$.

2. Der geplante Aufbau des Heeres erfolgt in Anlehnung an die Wehrgaueinteilung gem. Anlage $2^{94}$.

3. Die in den Jahren 1934 und 1935 beabsichtigten Massnahmen ergeben sich aus Anlage $3^{95}$.

4. Vorschläge für die Unterbringung der Gesamtplanungen im Bereich der Wehrkreise unter besonderer Berücksichtigung der Neuaufstellungen 1934-1935 sind spätestens zum 5. 2. 34 an das Rw.Min. (T.A.) in doppelter Ausfertigung mit 1 Ubersichtsskizze vorzulegen. (W. K. IV meldet für neue 3 . Div. $)^{96}$.

Gleichzeitig sind die im Haushaltsjahr 1934 anfallenden Kosten für die Unterbringung im Grossen zu melden ${ }^{97}$.

Bei den Vorschlägen für die Unterbringung ${ }^{98}$ sind folgende Punkte zu beachten:

a) Die Grenzdivisionen gem. Anl. 2 (grün unterstrichen) sind 1934 bevorzugt zu belegen. Dabei ist erwünscht, dieStandorte im Westen möglichst nahe an die demilitarisierte Zone und im Osten möglichst in oder dicht an die Rückhaltszone ${ }^{99} \mathrm{zu}$ legen.

b) Die nach den bisherigen Absichten bereits angelaufenen Unterbringungsplanungen sind möglichst beizubehalten.

c) Ergänzungsmannschaften ${ }^{100}$ fallen weg und sind nicht mehr zu berücksichtigen. Bereits begonnene oder vor dem Beginn stehende Baumassnahmen können unter den bisherigen Gesichtspunkten durchgeführt werden.

d) Neue Standorte können vorgesehen werden. Auf Standorte des früheren Heeres ist möglichst zurückzugreifen.

e) Die getrennten Standorte der Reiter-Regimenter sind zu vereinigen. Das Gleiche gilt für die noch getrennt liegenden Infanterie-Bataillone ${ }^{101}$. Die Angaben der Anlage 3 dienen als Anhalt.

f) Soweit für die geplanten Neuaufstellungen die Unterbringung in Standorten zeitlich nicht durchgeführt werden kann, ist vorübergehende Unterbringung auf Truppenübungsplätzen vorzusehen.

5. Wo die Unterbringung von Neuaufstellungen, die nach den bisherigen Planungen schon vorgesehen waren, feststeht, sind die noch vor dem 1.4. 1934 einzuleitenden Massnahmen (Sicherung des Grunderwerbs, Baupläne) sofort in Angriff zu nehmen.

Die Standortältesten und örtlichen Verwaltungsdienststellen können hierzu, soweit notwendig, herangezogen werden.

Die Beteiligung hat sich jedoch auf die Person des Standortältesten und bei den örtlichen Verwaltungsdienststellen auf die Vorstände der Heeresstandortverwaltungen ${ }^{\mathbf{1 0 2}}$ und Heeresbauverwaltungsämter ${ }^{103}$, gegebenenfalls auf einzelne Sachbearbeiter von ihnen zu beschränken.

Die erforderlichen Abschlüsse mit Behörden und Städten sind vorbehaltlich der Genehmigung durch den Herrn Minister zu tätigen.

Ưber Einzelheiten gehen den Wehrkreiskommandos bezw. Wehrkreisverwaltungsämtern ${ }^{104}$ Sonderweisungen $\mathrm{zu}^{105}$.

6. Wo in bisher nicht belegten Städten Erhebungen notwendig werden, können diese in streng vertraulicher Weise bei den betr. Landesfinanzamtspräsidenten bezw. Bürgermeistern durch die Intendanten oder durch Organe der Wehrkreisverwaltungsämter in Verbindung mit den Wehrkreiskommandos vorgenommen werden. Dabei sind alle beteiligten Stellen auf Geheimhaltung und grösste Einschränkung des Kreises der beteiligten Mitarbeiter hinzuweisen.

7. Die Durchführung ${ }^{106}$ der geplanten Neuaufstellungen und Umstellungen, sowie der genaue Zeitpunkt der vorgesehenen Verlegungen werden jeweils besonders befohlen. 
8. a) Der Schriftverkehr ${ }^{107}$ für den Heeresaufbau ist, wie bisher, unter "geh.Kommandosache« zu führen. Im Schriftverkehr innerhalb des Heeres können die richtigen Bezeichnungen der Einheiten angewendet werden.

b) Im schriftlichen und mündlichen Verkehr mit nicht militärischen Stellen sind Tarnbezeichnungen zu führen, z. B.:

schw.Art.Abt. - Art.Abt.

schw.F.H.Battr. - F.H.Battr.

Flak.Abt. - Art.Abt.

Flak.Battr. - Batterie

Kampfwagenkomp. - Kf.Komp.

Ist eine nähere Bezeichnung des Verbandes notwendig, so hat diese durch Hinzufügen des Standortes zu erfolgen, z.B. "2.Battr.Art.Abt. Spandau«.

9. Presseerörterungen ${ }^{108}$ über alle mit dem Heeresaufbau zusammenhängenden Massnahmen, insbesondere über die geplante Einrichtung neuer Standorte sind zu unterbinden.

I. A.

Beck

3. Niederschrift über die Besprechungen im Reichswehrministerium am 20. und 21. 12. 1933 zum Aufbau des 300000 -Mann-Heeres ${ }^{109}$.

BA-MA RH 53-7/1086.

\section{Teil}

Ausführungen des Reichswehrministers

Es ist nicht wahrscheinlich, daß es hinsichtlich der Abrüstung noch zu einer Konvention ${ }^{110}$ kommt; wenn nicht, müssen wir unabhängig vorgehen.

Umso wichtiger ist es, dass mit allen Mitteln auf Geheimhaltung und Tarnung ${ }^{111}$ hingewirkt wird; erzieherische Einwirkung auf das Offizierkorps usw. zur Verschwiegenheit.

Wenn wir den zum 1.4.34 einzuleitenden Massnahmen gewachsen sind, wird sich zeigen, dass wir die vergangenen Jahre richtig angewandt haben ${ }^{112}$. Es handelt sich dabei nicht um eine Improvisation, sondern alle Massnahmen müssen von Anfang an den Charakter einer festen Begründung tragen.

Daher:

1. nur einjährige Dienstzeit ${ }^{113}$

2. für 1934 zwar noch auf Freiwilligenbasis; nächstes Ziel ist aber Reichsdienstpflicht ${ }^{114}$.

3. sofortiger Ubergang zum 21-Div.-Heer mit 300000 Mann innerhalb von 4 Jahren. Es ist ausdrücklich verboten, von einem 21-Div.-Heer zu sprechen, besonders sind auch im Schriftverkehr alle derartigen Hinweise zu vermeiden. Es handelt sich vielmehr um eine Ausgestaltung der Wehrgaue ${ }^{115}$. Anträge auf Titelverleihungen (Div.Kdr. usw.) werden übelgenommen.

In der Wehrfrage gibt es zunächst zwei Hauptschwierigkeiten:

a) Die Regelung des Grenzschutzes ${ }^{116}$.

b) Die Bestrebungen der $\mathrm{SA}^{117}$, eine eigene Wehrmacht zu gründen.

Der Reichskanzler stimmt mit dem Reichswehrminister darin überein, dass ausser der vormilitärischen Ausbildung ${ }^{118}$ alles bei der Reichswehr liegt (Leitung und Vorbereitung der Aufstellung, mil. Ausbildung usw.). Auch die Führung in einem Kriege kann nur bei der Wehrmacht liegen. In den unteren Stellen soll um diese Grundsätze nicht gekämpft werden. Wo es Reibungen gibt, soll an den Rw.Minister kurz und sachlich berichtet werden (Minister weist auf W.K. $\mathrm{K}$. VII hin!) ${ }^{119}$. Diese Dinge müssen oben ausgefochten werden. Durch solche Schwierigkeiten darf das Verhältnis zur SA und ihren Führern nicht getrübt werden.

Offiziersbedarf:

1. Abkürzung der Ausbildung ${ }^{120}$. U. U. soll das Abiturientenexamen nicht mehr grundsätzlich verlangt werden (?) $)^{121}$.

2. Wiedereinstellung von ehemaligen Offizieren bis zum 40. Lebensjahre (aus L.O., Polizei, SA und privaten Berufen) $)^{122}$. 
3. Offiziere aus Unteroff.Stand ${ }^{123}$.

4. Abgabe von Offizieren aus Stäben (auch Truppen-Stäben). Keine Dienststelle hat mit Mehrzuweisung von Offizieren zu rechnen.

5. Zurückziehung der bei der SA kommandierten Offiziere ${ }^{124}$ zum 1.3. 34. Künftig keine langfristigen Kommandos mehr zur SA. Das Rw.Min. behält sich im Einzelfall derartige Kommandierungen vor. Offiziere, die dauernd bei der SA beschäftigt werden sollen oder wollen, sollen zur SA übertreten.

Einzelheiten:

a) In letzter Zeit ist verschiedenen Offizieren SA-Uniform ${ }^{125}$ verliehen worden; das Rw. Min. wird diese Frage im Auge behalten. Zu machen ist zunächst nichts dagegen.

b) Der Arier-Paragraph ${ }^{126}$ muss bei Fahnenjunker-Einstellungen und Verheiratungen berücksichtigt werden; wie weit sonst in dieser Hinsicht für das Offz.Korps noch Änderungen kommen, steht noch dahin.

c) Der Minister bittet die Befehlshaber, den Truppenteilen und Dienststellen seine besondere Anerkennung für die Leistungen im letzten Jahre auszusprechen.

Ausführungen des Chef T.A. ${ }^{127}$

Bedeutung der Geheimhaltung ${ }^{128}$. Nachdrückliche Einwirkung auf alle Stellen. Beschränkung des Kreises der Wissenden.

Der Umbau hängt ab:

a) von der aussenpolitischen Lage,

b) von dem personellen und materiellen Leistungsvermögen ${ }^{129}$,

c) von der Gründlichkeit aller Massnahmen,

d) von dem Zwang, so schnell als möglich, aus dem Zustand der völligen Wehrlosigkeit herauszukommen.

Geplant sind im Großen 3 Gruppen ${ }^{130}:-8$ A.K. (später 9$)^{131}-21$ Div. ${ }^{132}-3$ Reiter-Div. ${ }^{133}-1$ selbständige Reiter-Brigade ${ }^{134}-1$ leichte Div. ${ }^{135}-1$ Pz Verband ${ }^{136}$.

(Gruppe 31935 München) ${ }^{137}$

Div.: 3 I.R.

3 leichte, 1 schw. A.A.

$1 \mathrm{Pi}$

$1 \mathrm{Nach}$

$1 \mathrm{Kw} . \mathrm{Abw} . \mathrm{A} . \mathrm{A}$.

zu je 3 Einheiten

je W.K.K. Korps-Truppen:

1 s.A.R. (mot)

1 Beob.Abt.

1 FlakAbt.

$\left.\begin{array}{l}1 \text { Pi (mot) } \\ 1 \text { Nach(mot) }\end{array}\right\}$ zu je 3 Einheiten

Dazu je Gruko: (nur zahlenmässig, nicht unterstellt)

3 Flak-Abteilungen

1 Fla-M.G.Batl.

$1 \mathrm{Kw}$.Regt.

1 Nebel-Btl.

4 ReiterRegtr. werden bestimmt f. Bildung der A.A. der Div. Ob die A.A. schon friedensmässig gebildet werden sollen, wird noch geprüft.

Stärken: im Rahmen der $300000^{138}$

Beibehaltung der bisherigen Stärken R.H. (Ưbungsstärken) ${ }^{139}$.

Diese sind auch für Bauten zugrunde zu legen.

Div.Endstärke: $10200 \mathrm{Mann}^{140}$.

Um möglichst schnell Reserven ${ }^{141}$ zu schaffen, wird z. Zt. noch folgendes Verfahren geprüft (Befehle folgen):

1. 4. 34. Einstellung von 66000 Mann

30. 9. 34 Ausscheiden von 22000 Mann (der grössere Teil der am 1. 4. 33 Eingestellten) ${ }^{142}$ 
1. 10.34 60000 Mann neu (Diese Zusatzquote kommt auf jeden Fall; die endgültige Höhe wird noch bestimmt).

Der ganze Umbau ist auf ein Vierjahresprogramm ${ }^{143}$ eingestellt und zwar erfolgt die Hauptbelastung in den ersten Jahren, weil in diesen die Leistungsfähigkeit des R.H. noch grösser ist; nach der ersten Verwässerung erfolgt der Umbau langsamer.

Unterbringungsschwierigkeiten ${ }^{144}$ wird es höchstens im ersten Jahre geben; die erforderlichen Umbaumassnahmen ${ }^{145}$ müssen sofort einsetzen. Im ersten Jahr wird der Platz durch Zusammenrücken gewonnen werden müssen, durch Ubernahme aller Kasernen und u. U. Belegung von Ubungsplätzen.

Das nächste Ziel ist die Reichsdienstpflicht ${ }^{146}$ (Wehrpflicht oder Arbeitspflicht) mit Zwangsmusterung, Zeitpunkt wird noch befohlen. Er ist abhängig von der aussenpolitischen Lage. Möglichst im nächsten Sommer ${ }^{147}$.

1. 4. 34 Einstellung von Freiwilligen mit $1 \frac{1}{2}$ Jahren Dienstzeit.

1. 10. 34 Endgültiger Ubergang zur einjährigen Dienstzeit für Masse der Soldaten.

T.A. glaubt, dass die Aufbringung dieser Leute keinen Schwierigkeiten begegnet; für den Anfang werden die Altersgrenzen etwas weiter gesteckt. Massgebend für die Einstellung ist nur die mil. Eignung.

Das Kabinett hat bereits ein Gesetz über "Schutz der Freiwilligen « beschlossen. Diese sollen ein Vorrecht auf Arbeitsplätze haben. Auch im Rahmen der Reichsdienstpflicht ist noch möglichst freiwilliger Eintritt in das Heer anzustreben. Wer nicht Soldat werden will, kommt zum Arbeitsdienst ${ }^{148}$.

Die Leute des Arbeitsdienstes werden dann etwa der früheren Ers. Reserve gleichzustellen sein.

Spätere Absichten ${ }^{149}$ :

akt. Dienstzeit: ............................... 20.-23. Lebensjahr Reserve....... von der Entlassung bis zum 30. Lebensjahr einschliesslich (1 Res.Ubung)

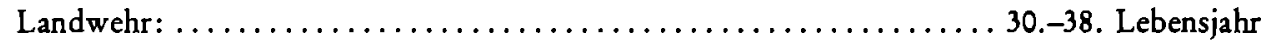

(1 Wiederholungsübung)

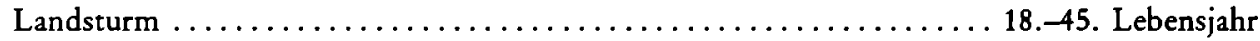

(soweit nicht gedient)

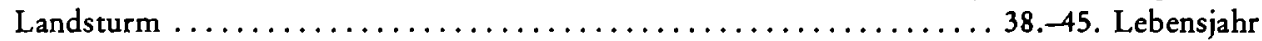

(soweit gedient)

Dislocierung:

Grundlage: Wehrgaue mit Änderungen (s. Karte - für Bayern Verlust von Unterfranken!) ${ }^{150}$ 21 Divisionen dürfen zunächst nicht in Erscheinung treten!

Änderung der Dienstbefugnisse der Wehrgaubefehlshaber ${ }^{151}$ am 1. 10. 34; Vorschläge der W.K.K. dazu erbeten.

Die personelle Ausstattung der W.K.K. Stäbe als K.K. wird noch geprüft ${ }^{152}$.

Provinz- und Regierungsbezirksgrenzen können nicht mehr berücksichtigt werden. Die Übereinstimmung der Grenzen hat unter den veränderten Verhältnissen ${ }^{\mathbf{1 5 3}}$ nicht mehr die alte Bedeutung.

Mit der Dienstpflicht entfällt die Vorbereitung von Meldestellen durch die Zivilbehörden. Festgehalten werden muss nur an der Forderung, dass einzelne Kreise bezw. Bezirksämter geschlossen zu bestimmten Wehrgauen gehören müssen; die Reichsreform ${ }^{154}$ wird ferner auch noch Änderungen bringen.

Die neue Einteilung unterscheidet zwischen "Grenzdivisionen « und "Innerdeutschen Divisionen «. Die Standorte der Grenzdivisionen (s. Karte) müssen so festgelegt werden, dass an besonders bedrohten Stellen gemischte Truppenverbände liegen. Eine Vermehrung der Grenzdivisionen im A-Falle ist zunächst nicht vorgesehen. Die "Divisionen Innerdeutschlands « ${ }^{155}$ (s. Karte) müssen sich später verdoppeln und ausserdem je eine Landwehr-Div. aufstellen. Die »Grenzdivisionen « ${ }^{156}$ stellen später 2 Landwehr Div. auf. Das gibt am Schluß 62 Divisionen und zwar: 32 Feld-Divisionen ${ }^{157}$ 
Unterbringung im einzelnen ${ }^{158}$ :

Vorschläge durch W.K.K.:

1. Mittlere und kleine Städte sind zu bevorzugen, grosse Städte nach Möglichkeit zu vermeiden, und möglichst nur mit mot. Truppen zu belegen.

2. Standorte der Grenzdivisionen sind vor allem nach taktischen Gesichtspunkten auszusuchen. (W.K. VII hat keine Grz.Div.).

3. Die Unterbringung nach dem bisherigen Umbauplan ${ }^{159}$ soll möglichst beibehalten werden.

4. Neue Standorte sind möglich. Zurückgreifen auf frühere St.O. ist erwünscht.

5. Die getrennte Unterbringung der Reiter Regimenter und der einzelnen Inf.Batlne ist baldmöglichst aufzuheben.

6. Unterbringung auf Übungsplätzen, wenn zunächst in den Standorten kein Platz.

Für die Berechnung des Unterbringungsraumes sind im Zweifelsfalle die höheren Stärken zugrunde zu legen, um eine Raumreserve zu haben.

II. Teil

Ausführungen des Chefs des T.A. - Fortsetzung ${ }^{160}$

Endziel ${ }^{161}$

1. $7 \%$ der Gesamtstärke Offiziere (bis Ende des 4. Jahres höchstens 3\% möglich)

2. $33 \%$ der Gesamtstärke länger Dienende

a) 2-3 Jahre

b) 10-12 Jahre.

Das Verhältnis der beiden Kategorien und die Frage der endgültigen Dienstzeit wird noch geprüft. Die W.Kdos. sollen Vorschläge machen. Bei 12 Jahren Dienstzeit ist beabsichtigt, dass die Kapitulanten vom 11. Dienstjahr an Zivil-Anwärter sind und unseren Etat nicht mehr belasten.

3. Rest $1 \mathrm{Jahr}$ (noch $1 \frac{1}{2}$ Jahre jedoch für die am 1. 4. 34 Eintreffenden).

Die 3 Monatsausbildung bei den Grenzschutzausbildungs Bataillonen ist beendigt ${ }^{162}$. Einberufungen noch einmal bis 31. 3. 34, dann gehen alle Grenzschutz-Bataillone in 21 Div. auf ${ }^{163}$

Aufstellung: Für das 1 . Umbaujahr wird am bisherigen A-Plan festgehalten ${ }^{164}$. Die A-Vorbereitungen 34/35 ändern sich daher nicht.

Grenzschutz-Ost und Grenzsicherung-West ${ }^{165}$ bleiben vorläufig wie bisher. Bestimmungen folgen noch.

Die Last der A-Vorarbeiten muss im Hinblick auf die Umbauarbeiten der Truppe auch möglichst wieder abgenommen und wieder der LO übertragen werden.

Für später ist entsprechend den Vorkriegsverhältnissen eine starke Dezentralisierung der Aufstellungs-Arbeiten beabsichtigt. Die W.Kdos stellen dann die A-Instruktionen für ihren Bereich auf.

Weitere Befehle in dieser Richtung folgen.

4. Gebeimbaltung und Tarnung ${ }^{166}$. Schriftverkehr in Umbau-Sachen wie bisher mit g.K. innerhalb des Heeres können die richtigen Bezeichnungen der Einheiten angewandt werden. Im Schriftverkehr mit nicht-militärischen Stellen sind Tarnbezeichnungen notwendig z.B. statt s.Art.Abt. = Art.Abt. Landshut

statt Kampfwagenabwehrabteilung Würzburg $=$ Kraftfahrabteilung Würzburg.

Von 21 Div. darf nicht gesprochen werden.

Die Presse ${ }^{167}$ darf keine Nachrichten über Einrichtungen neuer Standorte erfabren und bringen.

Die Landesbefestigung ${ }^{168}$ soll ebenfalls erweitert werden. Weitere Unterrichtung der W.Kdos folgt. Die W.Kdo.-Befehlshaber sind künftig nicht mehr wie bisher Bauherren. Die H.L. übernimmt der Einheitlichkeit halber die Leitung, ist aber auf die Unterstützung der W.Kdos angewiesen.

\section{SA-Ausbildung}

a) bis 1. 10. 34 bleibt unser Lehrpersonal bei der Reichsführerschule kommandiert ${ }^{169}$.

b) ausserdem sollen möglichst viele SA-Führer ausgebildet werden ${ }^{170}$. 
c) Einen Ersatz für die wegfallende 3 Monats-Ausbildung soll die Zusatzquote von Oktober 34 bringen.

d) Die Führerauswahl und -Ausbildung muss den tatsächlichen Verhältnissen Rechnung tragen, in vielen Fällen ohne Rücksicht auf die bisherigen Verdienste gewisser Leute.

Für den Grenzschutz sind neue Stellenbesetzungslisten vorzubereiten. Das Rw.M. befasst sich dabei höchstens mit Stellen bis zum Bataillons-Kommandeur einschl. abwärts. An der Spitze steht die Forderung der militärischen Eignung ${ }^{171}$.

Die Bezirkskommandos ${ }^{172}$ müssen vorläufig noch getarnt bleiben. Sie sind die Zubringer des Bedarfs an Freiwilligen und später Dienstpflichtigen.

Einzelfragen

a) Stellungnahme der W.Kdos. erbeten, ob bei jedem I.R. eine Radfabr-Kompagnie ${ }^{173}$ aufgestellt werden soll. Ein zusätzlicher Radfabr-Verband kommt jedoch nicht in Frage sondern nur die Umbildung einer Schützenkompagnie. Die Reiter-Züge der Inf.Rgter. werden den Regimentern unterstellt.

Führer möglichst Kav.Offiziere im Austausch mit Inf.Offizieren.

b) Uber das Schicksal der Polizei-Verbände ${ }^{174}$ ist noch nicht entschieden. Jedenfalls bleiben sie nicht in bisherigem Umfange. Solange die demilitarisierte Zone ${ }^{175}$ noch besteht, müssen wir an der Anzahl von Polizei-Verbänden ${ }^{176}$ festhalten

1. nach der Zahl der in der demilitarisierten Zone zugelassenen Verbände,

2. nach den Erfordernissen eines Mindest-Bedarfs für die Grenzsicherung-West ${ }^{177}$.

Abschluss:

Die Möglichkeit von verschiedenen Änderungen besteht noch.

III. Teil

Ausführungen des Chefs des P.A. ${ }^{178}$

Den W.Kdos gehen Fragebögen zu über Offiziers-Ersatz. Zu den Fragebögen können auch einzelne Offiziere (Kommandeure usw.) gehört werden. Sie dürfen aber nicht an nicht-militärische Stellen gegeben werden.

Die am 11. 11. bei der Befehlshaber-Besprechung bekannt gegebenen Zahlen für Offiziers-Ersatz sind überholt ${ }^{179}$.

Einstellung: 1. 4. 34: 1000 (statt 800);

1. 4. 35: 2000 (statt 1000).

An die Polizei soll wegen Ubernahme von Polizeioffizieren (bis zum 40. Lebensjahr) noch nicht herangetreten werden ${ }^{180}$.

Vom Major aufwärts wird nur aus dem Reichsheer befördert, abgesehen von der Ubernahme von $\mathrm{L}$-Offizieren (Reaktivierung von Major a. D. von Kiesling ist damit sichergestellt.).

Die Beförderungsverhältnisse ${ }^{181}$ im Reichsheer sollen durch die Übernahme ehemaliger Offiziere nicht beeinträchtigt werden.

Im ganzen sollen bis zu 1400 ehemalige Offiziere ${ }^{182}$ angestellt werden. Die W.Kdos können jederzeit Vorschläge an das Rw.M. machen. Offentliche Werbung darf nicht erfolgen. Die Landespolizei und die SA werden vom H.P.A. unterrichtet. Der Zeitpunkt für einzelne Verhandlungen wird vom Rw.M. dann noch befohlen.

Die IIa der W.Kdos können auf Antrag und Vorschlag einen L-Offizier als Hilfskraft bekommen ${ }^{183}$.

Aus der LO können auch einzelne, besonders geeignete Offiziere übernommen werden, die älter sind als 40 Jahre jedoch nicht in Kommandeur-Stellungen. Ehemalige Generäle können nur in der LO beschäftigt werden.

Zum 15. 2. 34 sind dem H.P.A. Vorschläge über Reaktivierung von L-Offizieren vorzulegen, zum 1. 7. 34 spätestens Vorschläge über Wiedereinstellung ehemaliger Offiziere.

Ubersicht über den Stand der Offiziere

Bei Zugrundelegung von $4 \%$ der Gesamtstärke ${ }^{184}$ waren am 1. 10.334500 Offiziere nötig, tatsächlich vorhanden 3800 .

Am 1. 10. 34 wären notwendig 9000 Offiziere, tatsächlich vorhanden 5800 . 
Wenn Wiedereinstellung von 1400 ehemaligen Offizieren möglich ist und eine Anzahl von Unteroffizieren ${ }^{185}$ vorgeschlagen werden kann, können wir am 1. 10.34 etwa 7300 Offiziere haben ${ }^{186}$. Das Verhältnis von $4 \%$ wird im Laufe des Umbaus erst wieder 1940 erreicht werden können.

Fübrerstabs-Offiziere ${ }^{187}$

1. Zurückziehung der Generalstabsoffiziere der Art.Fü.A

2. Bei den Div. gibt es künftig keine Chefs des Stabes mehr sondern nur Ia mit Chefbefugnissen ${ }^{188}$.

3. T.O. und Abwehr müssen vorübergehend mit einer grösseren Anzahl anderer Offiziere besetzt werden. Geplante 2. Führerstabs-Offiziere bei den Ib der W.Kdos. fallen weg.

4. Der 3. Lehrgang beim Rw.M. soll schon am 1. 4.34 beendet werden ${ }^{109}$.

\section{Ausfübrungen des Inspekteurs ${ }^{190}$}

Die 2jährige Ausbildung des Offiziers-Ersatzes für alle Waffen beginnt mit dem Einstellungstermin vom 1. 4. 34: 9 Monate Frontdienstzeit, 10 Monate Kriegsschule (gemischt) und Abschluss wie bisher 1 . Lehrgang. Waffenlehrgang von 3 Monaten für die Fähnriche nach näheren Anordnungen der Waffeninspekteure. Ziel: Ausbildung zum Rekrutenoffizier und Zugführer der betreffenden Waffe.

Uberblick über den Offiziers-Ersatz

31. 1. 34 Abschluss der z. Zt. laufenden Lehrgänge II $=250$ Fähnriche,

31. 10. 34 letzter Lehrgang II $=350$ Fähnriche,

31. 12. 34 dortiger Jahrgang 1933 (1. 5.-31. 12. auf Inf.Schule) ${ }^{191}=750$ Fähnriche.

1. 3.-31. 5. 35 Waffenlehrgang für diese 750 Fähnriche.

Damit beginnt der neue Ausbildungsplan!

Ausbildung 1934 in Dresden und an den Waffenschulen.

1935 Dresden, München ${ }^{192}$ (450), Hannover ${ }^{193}$ (450)

1936 Dresden, München, Hannover, Potsdam.

Die Waffenlehrgänge finden auf Übungsplätzen statt.

Nach 5 Jahren Offiziersdienst werden die Offiziere später auf 5 Monate zur wissenschaftlichen Wiederholung (bisher Lehrgänge II) zusammengezogen. Dies ist gleichzeitig Vorbereitung auf Wehrkreisprüfung. Abschlussprüfung $=$ Wehrkreisprüfung ${ }^{194}$.

IV. Teil

Ausführungen des Chefs des Wehramtes ${ }^{195}$

Mit den neuen Anordnungen ist der Übergang vom Söldnerheer ${ }^{196}$ zum Heer der Allgemeinen Dienstpflicht (wenn auch zunächst mit Einschränkungen) vollzogen. Daraufhin müssen wir uns in jeder Hinsicht einstellen (Ausbildung, Innendienst, Unterbringung, Versorgung).

Nach einem Kabinettbeschluss ist das Reichswehrministerium berechtigt, die Dienstzeit herabzusetzen ${ }^{197}$.

Die Versorgung ${ }^{198}$ der kurzdienenden Soldaten soll in 1. Linie durch ein Vorrecht auf einen Arbeitsplatz sichergestellt werden ${ }^{199}$. Von einer Wehrpflicht mit einjähriger Dienstzeit darf vorerst nicht gesprochen werden.

Die am 1. 4. 34 eintretenden Freiwilligen haben zunächst 11/2jährige Dienstzeit, ab 1. 10. 34 setzt die 1jährige Dienstzeit ein. Die entsprechenden Änderungen des Wehrgesetzes, des Besoldungsgesetzes und Wehrmachtsversorgungsgesetzes folgen ${ }^{200}$.

Künftige Besoldung im Monat etwa 65.- M. „Etwa 65.- M« erklärt sich aus den verschiedenen Sätzen der Bürgersteuer ${ }^{201}$ in einzelnen Standorten. Nach Abzug der Verpflegung erhält der $11 / 2$ Jahre dienende Mann voraussichtlich 1.- M Sold täglich.

Beim Ausscheiden ${ }^{202}$ erhält Jeder 75. - M für je $1 / 4$ Jahr Dienstzeit, ausserdem eine Ubergangsbeihilfe bis auf die Dauer eines halben Jahres wenn er nach dem Ausscheiden nicht sofort Arbeit findet. Diese Übergangsbeihilfe fällt weg, sobald ein Ausgeschiedener eine Arbeitsstelle gefunden hat.

Die späteren einjährigen Soldaten erhalten höchstens -.50 pro Tag bar.

Wegen endgültiger Festsetzung der Dienstzeit für die »länger dienenden « und das Verhältnis 
Anzahl von Truppenoffizieren zu einer Aussprache nach Berlin kommandiert. Die Befehlshaber sind darüber zu unterrichten. Die Truppenteile müssen sofort mit allem Nachdruck werben. Die am 1. 4. 1933 eingestellten Soldaten sind mit 30.9.34 zu entlassen, soweit sie nicht unter die "länger dienenden « fallen. Dies ist der Truppe jedoch noch nicht bekannt zugeben ${ }^{203}$.

Die ausgeschiedenen Soldaten sollen nach Möglichkeit für Ausbildungszwecke in S.A-Lager, Arbeitsdienst usw. abgegeben werden ${ }^{204}$.

Das Rw.Min. wird dahin wirken, dass die Polizei künftig unter den gleichen Bedingungen, wie das Reichsheer einstellt, sie soll später für ihre geschlossenen Verbände nur noch Leute nehmen, die zuerst $1 \mathrm{Jahr}$ im Reichsheer gedient haben. Die Kapitulanten sollen später dann in möglichst großem Umfang in Revierpolizei übernommen werden.

Auch wenn später die Reichsdienstpflicht kommt, sollen in 1. Linie in das Heer möglichst Freiwillige eingestellt werden. Für den Arbeitsdienst bleiben dann durchschnittlich immer noch rund $40 \%$ der einzelnen Jahrgänge ${ }^{205}$.

Bei der Truppe sollen auch künftig Soldaten vom Arbeitsdienst der Truppe möglichst freigemacht werden, dafür Arbeiter und Angestellte.

Ausführungen des Chefs der Allgemeinen Abteilung

Einstellung: Abfindung der kurz dienenden Soldaten ${ }^{206}$,

1. Gehalt etwa 65.- M, vgl. oben

2. Freifahrt zum Standort und zurück,

3. Abfindung von $M$ 225. 207

4. Ubergangsbeihilfe bis zur Gewinnung einer Arbeitsstelle, jedoch höchstens $1 / 2 \mathrm{Jahr}$.

5. Gesetzliches Vorrecht auf Unterbringung in eine Arbeitsstelle.

Für die in der Übergangszeit $1^{1 / 2} / 2$ Jahre Dienenden werden die Kündigungsfristen herabgesetzt, das Einspruchrecht wird beschränkt, die Entscheidung wird voraussichtlich dem W. Kdo übertragen. Bei den 12jährigen Soldaten bleibt es bei den bisherigen Verfahren ${ }^{208}$.

Für alle Truppenteile werden künftig die Obungsstärken in Kraft gesetzt. Diese werden jedoch noch überarbeitet und gehen bis Anfang Januar als Sammelheft ${ }^{209}$ dem W.K. zu. Auf Grund dieser Ubungsstärken läßt sich dann der endgültige Bedarf an Freiwilligen errechnen.

Dieser Bedarf ergibt sich

a) zum 1. 4. 34 auf volles Soll auf Grund der Übungsstärken, (Auffüllung der Fehlstellen),

b) Ersatz für Fehlstellen (durch planmässiges Ausscheiden bis 30. 9. 34)

c) Bedarf für Neuaufstellungen.

Zunächst kann festgestellt werden, welche Abgänge die einzelnen Truppenteile bis 30.9.34 haben (einschl. Abgabe an Luftwaffe.)

Werbung durch Truppe 210

Die Bezirkskommandos sollen der Truppe vor allem Leute zuleiten, die vormilitärische Ausbildung mit Erfolg durchgemacht haben. In der Übergangszeit bis zum 25. Lebensjahr.

San.In. setzt die Anforderung an Ersatz auf die Bedingungen der Vorkriegsersatzreservisten zurück $^{211}$. Verfg. folgt.

Zur Untersuchung der vielen Freiwilligen sind S.A. Ärzte und Vertragsärzte mit heranzuziehen.

Leute die nur für eine bestimmte Waffe nicht tauglich sind, sollen für andere Waffen tauglich geschrieben werden.

Die Bestimmungen über Sonderlaufbahn, Waffenmeister, Feuerwerker, Schirrmeister werden überarbeitet ${ }^{212}$.

An die Luftwaffe müssen im Laufe des Jahres $5700^{213}$ Köpfe abgegeben werden.

Der Abgabeplan wird im Laufe des Jahres 1934 abgehen.

Ausfübrungen des Chefs des Wehramtes

Die W.K.do's sollen nicht ängstlich sein bei der Übernahme alter Kasernen. Wo für die Ubernahme und Instandsetzung zu hohe Kosten entstehen, soll man lieber Neubauten errichten. Der Luxusbau ist zu Ende.

An Raumbedarf ${ }^{214}$ ist zugrunde zu legen:

für den kurz dienenden Mann 4,5 qm,

für den »länger dienenden« $7 \mathrm{qm}$ 
für den 12jährigen wie bisher.

Das gibt im Durchschnitt $6 \mathrm{qm}$ je Mann. In der Úbergangszeit muss u. U. unter diese Forderungen herabgegangen werden.

Der Raumbedarf für die Unterbringung der Truppenergänzungsbestände bleibt.

Ausrüstung mit Waffen und Gerät

Die Notausstattung soll allgemein auf Friedensausstattung gebracht werden, dazu sind mehrere Jahre notwendig. Im weiteren werden dann die A-Bestände wieder vermehrt, entsprechend den neuen A-Absichten ${ }^{215}$.

Die geplante Umlegung der Truppenergänzungsbestände muß durchgeführt werden. Bis September wird voraussichtlich bei verschiedenen Truppenteilen bereits der Friedensbedarf an Bewaffnung und A usrüstung usw. erfolgt sein. Ausstattung nach A. N. R. H. ${ }^{216}$. Die Instandsetzungsgelder werden künftig nicht mehr vom Rw.Min. verteilt. Die W.Kdo.'s erhalten Pauschalsummen überwiesen und verteilen diese an die einzelnen Einheiten zur Selbstbewirtschaftung je nach Bedarf (Umfang des zur Verwaltung gegebenen Gerätes etc).

Die Truppe erhält Arbeiter für die Verwaltung des Gerätes, soweit als möglich solche, die in der Beständeverwaltung frei werden.

Die Pferdelage wird noch auf mehrere Jahre sehr gespannt sein. Es sind daher weitgehende Eingriffe in die Pferdebestände der Truppe notwendig. Für eine Batterie werden in der Übergangszeit durchschnittlich höchstens 50 Pferde in Frage kommen.

Inf., sch.Art. usw. werden vorübergehend mit Kaltblut-Pferden auszustatten sein.

Bei der Bearbeitung der Haushaltmittel ist streng zu unterscheiden

a) weisse Haushaltmittel ${ }^{217}$,

b) $\mathbf{x}$-Mittel ${ }^{218}$

c) Sonderzuweisungen

d) Zufahrtmittel.

Getrennte Berechnung ist unbedingt erforderlich. Das Personal bei den W. K. (Haushaltbearbeiter und $\mathrm{Ib} / \mathrm{K}$ ) wird voraussichtlich verstärkt. Wenn auch das Geld künftig reichlicher fließt, ist doch mit allen Mitteln auf Sparsamkeit hinzuwirken.

V. Teil

Ausführungen des Chefs T.IV. ${ }^{219}$

Erläuterungen zur Ausbildungs-Verfügung.

Die Ubungsabsichten 1934 ermöglichen, soweit erforderlich Rekrutenausbildung auf Übungsplätzen.

Für Sonderausbildung im R.H. und ausserhalb des R.H. gilt:

Alle Kommandos zu S.A.-Sportlager werden mit 31.3. 34 aufgehoben. Sie sind künftig nur im beschränkten Umfang mit ausdrücklicher Genehmigung des Rw.Min. zugelassen.

Die in den Lehrtrupps tätigen aktiven Offiziere werden am 1.4.34 wieder reaktiviert und treten zur Truppe zurück 220 .

Sämtliche Lehrtrupps werden zum 1. 4. 34 aufgelöst. Schriftliche Verfügung folgt.

Das der S.A. auf Ubungsplätzen gewährte Gastrecht muss mit dem 1. 4. 34 ebenfalls aufhören.

Die S.A. muss zeitgerecht benachrichtigt werden.

Die bei den Grenzschutzausbildungs-Bat. tätigen aktiven Ausbildungstrupps hören mit 1.4. 34 auf (d. h. beim W. K. VII beginnen sie nicht).

Reservefübrer-Ausbildung ${ }^{221}$

soll mit besonderem Nachdruck betrieben werden (vor allem im Grenzgebiet). Es ist beabsichtigt eine möglichst grosse Anzahl von Reserveführern bis 1. 10. 34 zu gewinnen (bis Komp. Führer einschl.) Uber die Reserveführer-Ausbildung erfolgt noch Sonderbefehl; ab 1. 10. 34 wird die gesamte Reserveführerausbildung auf die Basis der einjährigen Dienstzeit abgestellt. Im Winter 34/35 kommt als besondere Aufgabe die Ausbildung der zu reaktivierenden Offiziere. Diese wird nach kurzer Dienstzeit auf 6 Monate in Offiziersschulen auf Ubungsplätzen zusammengezogen. Für die Infanterie ist je Gruppenkommando eine derartige Offiziersschule geplant. Die Aufstellung einer Lehrtruppe dafür wird besonders befohlen. Für die anderen Waffen sind entsprechende Kurse vorgesehen im Anschluss an Art.Schule, Pi.Schule, N.- und K. Schule. 
Neue Vorschriften ${ }^{222}$

A. V. I. nicht vor Herbst 1934.

Schiessvorschrift Gewehr, Pist., 1.MG. Herbst 34

Schiessvorschrift s.M.G. und M.W. Sommer 34

A.V.K. ?

A.V.A. zum Teil bereits im Druck.

A.V.Pi. Entwurf Sommer 34

Pi Dienst aller Waffen, 1. Entwurf fertig.

A.V.N. Herbst 34

A.V. Kraft?

Die auf die Hochschule kommandierten Offiziere kehren mit Ablauf des Wintersemesters zur Truppe zurück.

1 Selbst nach jüngsten Quellenfunden setzt G. Tessin: Deutsche Verbände und Truppen 1918-1939. Osnabrück 1974, S. 217 (zit. Tessin) sentscheidende Veränderungen « beim Heer erst auf den 1. 10. 1934 an.

B. Mueller-Hillebrand: Das Heer bis zum Kriegsbeginn. Darmstadt 1954 (= Das Heer 1933-1945. Bd 1.) - zit. Mueller-Hillebrand, übergeht die Zeit 1933/34 summarisch. K. D. Bracher, W. Sauer, G. Schulz: Die nationalsozialistische Machtergreifung. (= Schriften des Instituts für politische Wissenschaft. Bd 14.) Köln, Opladen 1960, S. 729 (zit. Bracher, Sauer, Schulz) gehen davon aus, daß ab 1. 4. 1933 »die Aufrüstung auf vollen Touren lief«. G. Wollstein: Vom Weimarer Revisionismus zu Hitler. Bonn 1973 (zit. Wollstein) stellt ohne Datierung der Rüstungspläne die außenpolitischen Verhandlungen über das 300000 Mann-Heer dar.

G. Meinck: Hitler und die deutsche Aufrüstung 1933-1937. Wiesbaden 1959 (= Veröffentlichungen des Instituts für Europäische Geschichte, Mainz. Bd 19.) - zit. Meinck, ist in dieser Frage überholt. M. Geyer: Militarismus, Aufrüstung und Landesverteidigung. Freiburg i. Br., Phil. Diss. 1976, legt alle drei Dokumente dem Kapitel "Rüstung und Außenpolitik. Eckdaten der Aufrüstung 1933-1934 « zugrunde. Ders. : Militär, Rüstung und Außenpolitik - Aspekte milizärischer Revisionspolitik in der Zwischenkriegszeit. In: Hitler, Deutschland und die Mächte. Düsseldorf 1976, S. 250-252 (zit. Geyer: Militär, Rüstung und Außenpolitik).

2 Grundlegend H.-A. Jacobsen: Die nationalsozialistische Außenpolitik 1933-1938. Frankfurt/M., Berlin 1968 (zit. Jacobsen); Bracher, Sauer, Schulz, passim. M. Messerschmidt: Die Wehrmacht im NSStaat. Zeit der Indoktrination. Hamburg 1969 (= Soldatische Menschenführung in der deutschen Militärgeschichte. 2.) (= Truppe und Verwaltung. Bd 16.) - zit. Messerschmidt: Die Wehrmacht im NSStaat.

K.-J. Müller: Das Heer und Hitler. Armee und nationalsozialistisches Regime 1933-1940. Stuttgart 1969 (zit. Müller: Das Heer und Hitler); Jacobsen, S. 401, zitiert aus der Denkschrift v. 14. 12. 1933. Neuerdings G. Schulz: Deutschland seit dem Ersten Weltkrieg 1918-1945. Göttingen 1976 (= Deutsche Geschichte. Hrsg. von J. Leuschner. Bd 10.)

3 Auch in neuesten Veröffentlichungen Hitler, Deutschland und die Mächte. Materialien zur Außenpolitik des Dritten Reiches. Hrsg.: M. Funke. Düsseldorf 1976 (= Bonner Schriften zur Politik und Zeitgeschichte. Bd 12.) - zit. Hitler, Deutschland und die Mächte, finden sich im Teil "Instrumentarium * nur Aufsätze zur materiellen Rüstung oder theoretisch angelegte Analysen.

4 M. Geyer: Das Zweite Rüstungsprogramm (1930-1934). In: MGM 17 (1975) 125-172 (zit. Geyer: Das Zweite Rüstungsprogramm).

5 Umbauplan des Friedensheeres. Chef HL T.A. Nr. 737/32 gKdos T2 III B v. 7. 11. 1932. Bundesarchiv-Militärarchiv, Freiburg i. Br. (BA-MA) RH 15/11.

Dieser "Milizplan« war in drei Abschnitten zu verwirklichen (1933-1938), er war auch bindende Grundlage für organisatorische Umbauarbeiten im Jahre 1933. Die Struktur des neuen Friedensheeres: stufenweise Erhöhung des langdienenden Personals auf 144000 Mann (Rahmenheer) zusätzlich 85000 Mann jährlich an Ergänzungsmannschaften (Miliz).

6 Weisung vom März 1931, Politisches Archiv des Auswärtigen Amtes (PA) II F Abr. Del. Nr. 1-3/1 Weisungen.

7 Chr. Fraser: Der Austritt Deutschlands aus dem Völkerbund, seine Vorgeschichte und seine Wirkungen. Bonn, Phil. Diss. 1969; Wollstein, S. 229ff.; H.-J. Rautenberg: Deutsche Rüstungspolitik vom Beginn der Genfer Abrüstungskonferenz bis zur Wiedereinführung der Allgemeinen Wehrpflicht 1932-1935. Bonn, Phil. Diss. 1971, S. 149ff. (zit. Rautenberg).

- In diesem Sinne äußerte sich auch Reichsaußenminister v. Neurath vor dem IMT. Der Prozeß gegen die Hauptkriegsverbrecher vor dem Internationalen Militärgerichtshof Nürnberg. Bd 17. Nürnberg 1948 , S. 229 (zit. IMT); Wollstein, S. 190ff., betont das starke Interesse der Reichswehrführung und vor allem Blombergs. 
9 Besuch des brit. Botschafters. Aufzeichnung des RAM v. 24. 10. 1933 PA, II F Abr. Abr. 30/9. Auch Documents on German Foreign Policy. 1918-1945. C/II/53 (zit. DGFP).

10 Besuch des französischen Botschafters bei Staatssekretär (Stŝे. Bülow am 5. 12.und 7. 12. 1933. Aufzeichnung v. Bülow. PA, Büro Sts AD/6. Auch DGFP, C/II/100 und C/II/105. Im Verlauf des Gespräches am 5. 12. bezog sich Franrois-Poncet auf frühere Äußerungen Hitlers und am 7. 12. gab er sein Gespräch mit Hitler am 24. 11. 1933 inhaltlich Sts v. Bülow zur Kenntnis.

11 Runderlaß des AA v. 27. 11. 1933, in dem die jüngsten diplomatischen Kontakte mit den beiden Botschaftern kommentiert wurden. Bundesarchiv, Koblenz (BA) R2/5342.

12 Das Rüstungsproblem stellte sich zu diesem Zeitpunkt nur noch alternativ dar. »Es handelt sich um eine Wahl zwischen begrenzter Aufrüstung auf der einen und unbegrenzter auf der anderen Seite. « Sir John Simon, Unterhausrede v, 24. 11. 1933. Meinck, S. 63 -Die französische Regierung sei durch die Haushaltsdebatte abgelenkt, danach erst werde sie sich der deutsch-französischen Aussprache wieder zuwenden können. Besuch des franz. Botschafters bei Sts v. Bülow am 7. 12. 1933. Vgl. Anm. 10 und Wollstein, S. 229ff. Insgesamt wurde im Ausland die neue Grundrichtung akzeptiert: Keine »Abrüstung ${ }^{*}$, bestenfalls » Rüstungsbegrenzung «.

13 Text in Ursachen und Folgen. Vom Deutschen Zusammenbruch 1918 und 1945 bis zur staatlichen Neuordnung Deutschlands in der Gegenwart. Bd 10. Berlin 1965, S. 60-63 (zit. Ursachen und Folgen). In diplomatischen Gesprächen, die diesem Memorandum unmittelbar vorausgingen, war deutscherseits daran erinnert worden, daß auf der Versailler Friedenskonferenz ein deutscher Heeresumfang von 300000 Mann bereits einmal zur Debatte gestanden hatte. Aufzeichnung Schwendemann v. 15. 12. 1933. PA II F Abr. Abr. 5 Nr. D, Bd 3.

14 Text in Ursachen und Folgen, Bd 10, S. 74-76

15 Siehe Anm. 4.

16 Einzelheiten s. Anm. 142.

17 Hitler im Reichskabinett am 12. 5. 1933. BA R 43/I/1462.

18 Allgemein K. H. Völker: Die deutsche Luftwaffe 1933-1939. Stuttgart 1967 (zit. Völker I); ders. : Dokumente und Dokumentarfotos zur Geschichte der Luftwaffe. Stuttgart 1968 (zit. Völker II).

Zum Vergleich drei Programme:

1.) "1000 Flugzeuge-Programm v. 1. 2. 1932*

2.) " 600 Flugzeuge-Programm v. 29. 6. 1933 a

3.) "Flugzeugbeschaffungsprogramm v. 1. 7. 1934 - 4021 Flugzeuge bis zum 30. 9. 1935«

Vgl. Rautenberg, S. 317 ff. und Anhang, S. 87; dort auch Belege.

19 F. Hoßbach: Zwischen Wehrmacht und Hitler 1934-1938. Göttingen 21965, S. 66 (zit. Hoßbach).

20 Hoßbach, S. 20 u. 53. Ebd., S. 60, auch die erste belegbare Weisung Hitlers an den neuernannten Chef der Heeresleitung, Gen. Frhr. v. Fritsch: "Schaffen Sie mir ein Heer in größtmöglicher Stärke und innerer Geschlossenheit und auf dem denkbar besten Ausbildungsstand.

21 Material: BA-MA Wi/I F5/499, 511; RH 15/34, 49. RH 15/2. Die nachstehende Ubersicht beschränkt sich auf den Kern des Heeres, die sieben Infanteriedivisionen. Aus Gründen der vereinfachenden Darstellung, die der Grundlinie folgt, wurden Folgepläne, die sich aus den Planzielen jeweils ergaben, nicht berücksichtigt.

22 Vgl. Dok. 3 und Anm. 119.

23 H. Hoehne: Der Orden unter dem Totenkopf. Die Geschichte der SS. Gütersloh 1967, S. 92; E. Neusüß-Hunkel: Die SS. Hannover, Frankfurt/M. 1956, S. 12; K.-J. Müller: Reichswehr und »Röhm-Affäre«. Aus den Akten des Wehrkreiskommandos (Bayer.) VII. In: MGM 3 (1968) 107-144, bes. S. 107-118); H. Bennecke: Die Reichswehr und der Röhmputsch. München 1964 (= Beihefte der Zweimonatsschrift Politische Studien. H. 2.)

24 Dokumentierte Belege zum Verhältnis SA und Reichswehr in Ursachen und Folgen, Bd 10, Kap. VII: Die Auseinandersetzungen zwischen Reichswehr und SA, S. $111 \mathrm{ff}$.

$25 \mathrm{Vgl}$. die Ausführung des Reichswehrministers v. Blomberg auf der Befehlshaberbesprechung in Bad Wildungen am 1. 6. 1933. Institut für Zeitgeschichte (IfZ) - Liebmann-Notizen - 167/51.

26 Vgl. die Ausführungen des Reichswehrministers, Dok. 3.

27 Vgl. die Denkschrift v. 14. 12. 1933 Dok. 1.

28 Ende März/Anfang April 1933 kursierten in Europa Präventivkriegsgerüchte. In einer Kabinettssitzung v. 15. 4. 1933 berichtete Reichsaußenminister v. Neurath darüber; er bezeichnete die entsprechenden Berichte aus Prag und Warschau als "nicht beunruhigend ", sie seien für die politische Lage eher "vorteilhaft «, es ergebe sich aber die "unbedingte Notwendigkeit « für eine Verstärkung der Wehrmacht. BA R 43/I/1461. Diplomatiegeschichtliche Einzelheiten bei Rautenberg, S. 398-400; und bei Wollstein, S. $122 \mathrm{ff}$.

29 So Geyer: Militär, Rüstung und Außenpolitik, S. 239, für Weimarer Regierungen. Der Gedanke der Bündnisfähigkeit tauchte nur noch einmal in dem Vortrag von GenMaj Liese, Chef Heereswaffenamt (H.Wa.A.), zur »Rüstungslage Deutschlands» v. Mai 1934 auf. Vgl. Anm. 55.

30 Geyer: Militär, Rüstung und Außenpolitik, S. 258.

31 Vgl. IMT, Bd 36 (1949), Dok. EC 404; Sitzungsbericht der 6. Sitzung des Arbeitsausschusses des Reichsverteidigungsrates v. 7. 2. 1934.

32 Der Reichsverteidigungsminister (v. Blomberg) Nr. $3 / 33$ gKdos v. 17. 10. 1933. BA-MA II M 100/32.

33 Text bei Müller: Das Heer und Hitler, Dok. 25.

34 BZ Nr. 2064/29 „Z« v. 12. 12. 1929. BA-MA II/M/2.

35 T. A. - unsigniert; Vortragsnotizen über Organisation des RWM. Jan. 1934. BA-MA H 1/319b. 
36 Vortragsnotiz vom Jan. 1934; vgl. Anm. 35. Denkschrift Gen Beck v. 20. 5. 1934. BA-MA, Nachlaß Beck, N 28/1. Ergänzend auch Chef des T. A. Spitzengliederung v. 15. 1. 1934, Text bei Müller: Das Heer und Hirler, Dok. 27.

37 T. A. Nr. 355/33 T2 II v. 21. 11. 1933. - BA-MA RH 15/34.

$38 \mathrm{Vgl}$. Anm. 5. Zum Vergleich Wehrplan v. 7. 11. 1932, Anl.1 - Neuaufstellung Infanterie: $63 \mathrm{Kpfw}$. Abw. Zg. - Weisung v. 21. 11. 1933 - Genehmigte Vorhaben Infanterie für 1934: „Aufstellung von 71 Kpfw. Abw. Zügen (63 Inf. Btl. u. 8 A. Btl.).

39 Chef HL T.A. Nr. $359 / 33$ gKdos T2 v. 30. 11. 1933. Vgl. Anm. 93.

40 Dok. 1. Oberstlt Sodenstern hatte die Leitung der T2 am 1. 10. 1933 übernommen. Vorgänger Oberst W. Keitel.

41 Fundstelle der Denkschrift AHA Ref. III, Schriftverkehr über den Aufbau des Heeres v. 18. 12. 1933 23. 3. 1934. Wenn ich es recht übersehe, sind Akten aus dem T. A. vornehmlich der Abteilungen T1, T2, T4, zur Vorgeschichte der Denkschrift nicht erhalten. BA-MA RH 15/34.

42 Chef HL T.A. Nr. 350/33 gKdos T2 III/IB v. 27. 4. 1933 (Hammerstein) BA-MA RH 15/v. 28. Grundlegend auch in diesem Fall Wehrplan v. 7. 11. 1932, Anl. 1 "Neu aufzustellen, Stäbe: 21 Territorialstäbe unter Verwendung der Infanterieführerstäbe und einiger Kommandanturen. *

43 Mit Befehl v. 27. 4. 1933 geregelt. Vgl. Anm. 42.

44 Vgl. Anm. 13.

45 Die Liebmann-Notizen (IfZ 167/51) dokumentieren die tatsächlich stattgefundenen Befehlshaberbesprechungen nicht vollständig. Die Besprechung v. 11. 11. 1933, auf die sich Chef PA (Dok. 3) bei seinen Ausführungen bezieht, ist nicht aufgeführt; sie muß als verschollen gelten. Ebenso fehlt die Besprechung v. 20./21. 12. 1933 in den Liebmann-Notizen. Sie ist zwar nicht ausdrücklich mit "Befehlshaberbesprechung « betitelt, doch lassen Umfang und vor allem die hohen Dienststellungen der Vortragenden zweifellos darauf schließen, daß die Adressaten nur die Spitzen der Reichswehr gewesen sein können.

46 Vgl. Chef PA "Reaktivierung von Major a. D. v. Kiesling ist damit sichergestellt. " Und Chef T. A. "Dislozierung - Verlust von Unterfranken «.

47 RWM Nr. $750 / 33$ gKdos Wehr A/Allg. III a. v. 20. 12. 1933. BA-MA 53-7/1086.

48 Chef HL am 1. 2. 1934, Frhr. v. Fritsch: "Ich fand einen Trümmerhaufen vor . . . Hoßbach, S. 60.

49 Müller: Das Heer und Hitler, S. 208.

so Ebd.

51 Kommandeurbesprechung am 15./18. 1. 1934 in Stuttgart und Kassel. Liebmann-Notizen (IfZ $167 / 51$ ).

52 Stempel Geheime Kommandosache. Stempel Wehramt, handschriftlich 19. 12. 1933. Paraphe Chef, Fromm. Fundstelle BA-MA RH 15/34. Der Chef der Heeresleitung, T. A. 1113/33 gKdos T2 III B. 25 Ausfertigungen. 6. Ausfertigung.

53 Ausdruck des Risikogedankens, der sich durch die ganze Aufbauphase zieht. Dem Risikogedanken haftete immerhin noch militärische Rationalität an. Mehr einem Zugeständnis an den "Zeitgeist a entsprang Blombergs Weisung zur Reichsverteidigung v. 25. 10. 1933, "ohne Rücksicht auf militärische Erfolgsaussicht ", jedem feindlichen Vorgehen Widerstand zu leisten. (IMT, Bd 34 (1949), S. 488f.) Die Sanktionsgefahr selbst war schon im April 1933 gering eingeschätzt worden.

54 Fast auf den Tag genau (7. 12. 1933) brach im RWM ein "Denkschriftenkrieg « über die Organisation der milit. Spitzenbehörden aus. Die ungelösten Probleme der Spitzengliederung, Reflex der allgemeinen Organisationsprobleme, belasteten die Wehrmacht während der Aufbauphase und bis in den Krieg hinein. Ausführlich Müller: Das Heer und Hitler, S. 205ff.; Rautenberg, S. 332ff.

55 Umfassend in Analyse und Darstellung Denkschrift des Heereswaffenamtes - GenMaj Liese - „Die Rüstungslage Deutschlands wie sie sich augenblicklich und voraussichtlich in den nächsten Jahren im Falle eines Krieges darstellt. « v. 9. 5. 1934, H.Wa. A. Nr. 875/34 gKdos Wi I. BA-MA Wi/F5/1638. Einzelheiten s. Anm. 129.

Geyer: Das Zweite Rüstungsprogramm; ders.: Militär, Rüstung und Außenpolitik.

56 Zum Vergleich Planziel Kriegsheer $(1933)=63$ Div. Mobilmachung $1939=102$ Div.

57 Indiz für die Absicht der militärischen Führung, im Falle eines bewaffneten Konfliktes den Krieg auBerhalb der deutschen Grenzen zu führen.

Tatsächlicher Stand der Vorbereitung der Landesverteidigung - In erster Linie muß mit der Besetzung deutscher Landesteile gerechnet werden. « Widerstand leisten »ohne Rücksicht auf militärische Erfolgsaussicht «.

Weisung betr. geheime Verteidigungsmaßnahmen (Blomberg) v. 25. 10. 1933 IMT, Bd 34 (1949), S. 488ff. Siehe auch Anm. 53.

58 Neuere Forschungsergebnisse H.-E. Volkmann: Politik, Wirtschaft und Aufrüstung unter dem Nationalsozialismus; W. A. Boelcke: Zur internationalen Geldpolitik des NS-Staates. Ein Beitrag zur deutschen Währungs- und Außenwirtschaftspolitik 1933-1945. Beide in Hitler, Deutschland und die Mächte (s. Anm. 3), S. 269-309.

s9 Nicht wiedergegeben. Gliederung der Felddivision (1933) ist identisch mit aktiver Division (1939, 1. Welle). Allerdings war die Personalausstattung der drei Inf.Rgter (1933) geringer. Daraus erklärt sich die Differenz in den Stärken der fechtenden Truppe.
Felddivision
$(1933)=10200$ Mann
Inf.Div.
$(1933)=15000$ Mann 
Einzelheiten zur Gliederung der Kriegs- und Friedensverbände 1939 s. bei Mueller-Hillebrand, Anlagen.

60 Nicht wiedergegeben. Das dt. Heer verfügte bei Kriegsausbruch über keine Kav.Div. mehr, nur noch über eine Kav.Brig.

61 Nicht wiedergegeben. Die leichte Div. (1939) verfügte gegenüber der geplanten von 1933 über eine stärkere Inf. Komponente.

62 Nicht wiedergegeben. Die Pz.Div. von 1939 verfügten gegenüber dem geplanten Pz.-Verband von 1933 über eine wesentlich stärkere Pz.-Ausstattung.

Neuerdings K. J. Walde: Guderian. Frankfurt/M., Berlin, Wien 1976, S. 37-61; K. J. Macksey: Guderian, Panzer General. London 1975; ders.: Panzer Division the mailed fist. New York 1972. Mit einigen Ungenauigkeiten W. K. Nehring: Die Geschichte der deutschen Panzerwaffe 1916-1945. Berlin 1969. Aus der Sicht eines DDR-Forschers R. Barthel: Theorie und Praxis der Heeresmotorisierung im faschistischen Deutschland bis 1939. Leipzig, Phil. Diss. 1967.

63 Trotz der Aufstellung des Reichsluftfahrtministeriums (RLM), dem Vorläufer des dritten Wehrmachtteiles, der Luftwaffe, war zu diesem Zeitpunkt die Unterstellung der Fliegerkräfte im Kriegsfall noch nicht endgültig geklärt. In der Weisung Blombergs v. 25. 10. 1933 im Falle von Sanktionen hieß es: „Die für Heer und Marine vorgesehenen Luftstreitkräfte sind, sobald ihre Aufstellung beendet ist, dem Chef des Heeres- bzw. Marineleitung zu unterstellen. «(Ursachen und Folgen, Bd 10, S. 48). Zum Aufbau der Luftwaffe Einzelheiten bei Völker I und II. Vgl. auch Anm. 213.

64 Terminus "Allgemeine Dienstpflicht « (Wehrdienst und/oder Arbeitsdienst) für die Zeit zwischen dem Anlaufen der Wehrreform auf der Grundlage dieser Denkschrift und der tatsächlichen Wiedereinführung der Allgemeinen Wehrpflicht am 16. 3. 1935. Das Protokoll der Befehlshaberbesprechung v. 15./18. 1. 1934 vermerkt lapidar: $₫ 100000$ Mann-Heer endet am 1. 4. 1934* Liebmann-Notizen (IfZ $167 / 51$ ).

65 Mit der Verkündung des Wehrgesetzes v. 21. 5. 1935 wurde die Dauer des aktiven Wehrdienstes auf zunächst 1 Jahr festgelegt. Ab 1. 10. 1936 dann auf 2 Jahre. Ein unentbehrliches Handbuch zum Dienst-, Laufbahn- und Versorgungsrecht, zur Wehrverfassung und zum Inneren Dienst in der Reichswehr und in der Wehrmacht bildet das dreibändige Werk von R. Absolon: Die Wehrmacht im Dritten Reich. Bd 1-3. Boppard a. Rh. 1969-1975 (= Schriften des Bundesarchivs. Bd 16, 1-3) - zit. Absolon I, II, III.

66 Es bestanden 9 Grenzschutzausbildungsbtle. "In der Aufbauzeit soll die Ausbildung des Grenzschutzes durch insgesamt 27 Batl. vorgenommen werden. "Vorschlag für den Aufbau des Friedensheeres in 4 Jahren. Anl. 6 (nicht wiedergegeben). Entsprechend der Verdreifachung des Heeres sollte also auch der Grenzschutz verdreifacht werden. Zwischen dem 14. 12. und dem 21. 12. 1933 ist Gegenbefehl ergangen (nicht mehr feststellbar). Chef T. A. stellt am 21. 12. 1933 fest: "Die 3 Monatsausbildung bei den Grenzschutzausbildungs-Bataillonen ist beendigt. "Vgl. Dok. 3, Anm. 162.

67 Die $18 \mathrm{GrzSchABtl}$ wurden nicht mehr aufgestellt. Vgl. Anm. 66 und die Ausführungen des Chefs T4 (Dok. 3).

68 Diese Bemerkung wirft indirekt ein dekuvrierendes Licht auf den militärischen Wert aller geheimen Rüstungsmaßnahmen während der Weimarer Republik.

69 Siehe Anm. 53. Strategisch sind vier Stufen zu unterscheiden: 1. Nicht Krieg führen können. 2. Krieg verhindern können. 3. Krieg abwehren können. 4. Krieg führen können.

70 Antinomie des Heeresaufbaues. Schnelligkeit im Aufbau, Qualitätserhalt und Reservenbildung waren konkurrierende Ziele. Der Zielkonflikt wurde im Sinne eines schnellen Aufbaues und der Bildung personeller Reserven gelöst; Vorschlag des AHA vom Mai 1934, die Aufstellung des 300000 Mann-Heeres bereits auf den 1. 10. 1934 vorzuziehen. Gen Beck und die Heeresleitung unter Gen Frhr. v. Fritsch gaben dem Qualitätserhalt Vorzug. "Der beabsichtigte rasche Umbau des Heeres (ist) nur denkbar, wenn der innere Wert und die Leistungen des 100000 Mann-Heeres sich auf der Höhe zeigen wie bisher. « Befehlshaberbesprechung v. 15./18. 1. 1934. Liebmann-Notizen (IfZ 167/51). Vgl. auch Müller: Das Heer und Hitler, S. 208f.; Rautenberg, 309f.

71 Wann und ob Hitler einen zustimmenden Entscheid getroffen hat, ist nicht mit Sicherheit festzustellen. Die Quellen schweigen dazu. Wenn ein solcher Entscheid erfolgt ist, dann vermutlich in der ersten Dezemberwoche. Jacobsen, S. 400, geht davon aus, Hitler habe »den Wehrmachtspitzen entsprechend der Auftragstaktik Handlungsfreiheit für die Ausführung im einzelnen « gewährt.

72 „Vorschlag für den Aufbau des Friedensheeres in 4 Jahren « nicht wiedergegeben. Der Vorschlag ist eine auf die Etatjahre 1934-1937 verteilte Aufschlüsselung vorhandener und aufzustellender Verbände der Btl.- und Einheitsebene.

73 Anl. 7 nicht wiedergegeben. Gliederung des 21 Div.-Heeres wie vom Chef T.A. unter Ziff. IId am 20./21. 12. 1933 (Dok. 3) vorgetragen. Die Anl. 8 ist als einzige wiedergegeben; aus ihr läßt sich die Struktur des neuen Friedensheeres, vor allem in zahlenmäßiger Hinsicht gut ablesen.

74 Nicht wiedergegeben. „Ubersichtsskizze der Unterbringungsräume von 21 Divisionen und 1 le. Div. «; Wehrgaueinteilung, vgl. Anm. 116.

75 Vgl. Ausführungen Chef T. A. - Fortsetzung - „Endziel « Dok. 3.

76 Beide Anlagen sind nicht wiedergegeben. Der Begriff »Allgemeine Wehrpflicht « taucht hier erstmals auf. Vgl. auch die Ausführungen des Chefs T. A., Dok. 3, Anm. 149; sie sind inhaltlich mit den beiden Anlagen identisch.

77 Pzkw = Panzerkraftwagen; die Pzkw-Truppe zählte zu den Kraftfahrtruppen. Kpfw = Kampfwagen. Die Kpfw-Truppe zählte zur Panzertruppe.

78 Zum Vergleich: Nach dem »Plan zur Organisation des neuen Friedensheeres» v. 7. 11. 1932 (vgl. Anm. 
5), der grob gesprochen eine Verdoppelung des aktiven Heeres zum Ziel hatte, wären im Jahresdurchschnitt ca. 100000 Mann personeller Reserven angefallen.

79 Ehemalige Offz. $=1400 ;$ Bereitschaftspolizei $=600$.

so Dem Reichsheer war It. VV bei einer Gesamtstärke von 100000 Mann ein Offizierkorps von 4000 Köpfen $(4 \%)$ zugestanden worden. Damit war der Offizierbestand bewußt unter der Verhältniszahl Offizier: Mannschaft gehalten worden, mit dem die vielfältigen Aufgaben einer modernen Truppenführung noch bewältigt werden konnten.

Bezugsgröße für die hier genannte Zahl von $3 \%$ war aber nicht mehr das 100000 Mann-Heer, sondern das neue Friedensheer von 300000 Mann. Daher entsprachen $3 \%=9000$ Offizieren. Legt man das Endziel von $7 \%=21000$ Offiziere zugrunde, was für eine moderne Truppe schon als untere Grenze angesehen wurde, so war die Reichswehrführung bereit, mit weit weniger als der Hälfte der benötigten Offiziere die Aufbauzeit zu bestehen.

81 Vgl. Dok. 3, Anm. 123.

82 Siehe Anm. 174.

83 Ideologische Formel im Konflikt mit der SA, zugleich aber auch als Petitum an die Adresse Blombergs, rückblickend auch Frhr. v. Fritsch: "Mit mir war wohl jeder einsichtige Soldat der Auffassung, daß an Stelle der Armee die SA treten sollte, wenn dies auch immer wieder von Blomberg und Reichenau in Abrede gestellt wurde." Hoßbach, S. 60.

84 Vgl. Anm. 55 und 129.

Bs. "Für die Rüstungsvorbereitungen des Notstandsheeres mussten die Gebiete festgelegt werden, die einem unmittelbaren feindlichen Zugriff nicht ausgesetzt sind, in denen allein es sich lohnte, fabrikatorische Vorbereitungen und Neuerrichtung von Betrieben . . . zu treffen«. Liese, Chef H.Wa.A. vom Mai 1934, BA-MA Wi/IF 5/1638.

869 (akt.) Div. (im Reichsinnern)

3 (akt.) Div. (Ostpreußen)

9 (akt.) Div. (Grenzdivisionen) 21 (akt.) Div.

87 Vgl. Anm. 117.

88 Siehe Anm. 165 .

89 Reichswehrzwischenbefehlsstellen: Am 15.11.1933 erhielten durch Verfügung des RMI einige Landespolizei-Inspektionen diese Bezeichnung. So Stuttgart für Württemberg und Baden. Sie waren verantwortlich für die Mob-Mạßnahmen der Polizei und ihre truppenmäßige Ausbildung. Tessin, $S$. 459.

90 Stempel Geheime Kommandosache. Außenverteiler bis zu Divisionsebene. Verschiedene Bearbeitungsvermerke. Paraphe Fromm, 22. 12. 1933. Fundstelle BA-MA RH 15/34.

Der Chef der Heeresleitung. T. A. Nr. 301/33 gKdos T2 II v. 18. 12. 1933.

91 Siehe Anm. 93.

92 Nicht wiedergegeben. Stärken und Gliederung der Großverbände wie von Chef T.A. am 20./21. 12. 1933 (Dok. 3, Ziff. IId) vorgetragen. Vgl. auch Dok. Anl. 8.

93 Umbauplan, Chef HL T. A. Nr. 359/33 gKdos T2 II v. 30. 11. 1933, nicht mehr auffindbar. Nebenstehender Vermerk: »ist vernichtet*. Einiges spricht für die Vermutung, daß aufgehobener Umbauplan mit der Weisung T. A. Nr. 355/33 gKdos T2 II v. 21. 11. 1933 inhaltlich identisch ist. (Bearbeitungsstelle in beiden Fällen T2 II; Herausgabedaten und Erlaßnummern liegen eng beieinander) BA-MA RH 15/34. Dieser Rahmenplan für den Umbau des Heeres 1934 lehnte sich mit seinen bescheidenen Zielen noch eng an den Umbauplan v. 7. 11. 1932 an. Einige Plandaten sind bis auf die Ziffer genau der Ubersicht über den Umbau des Heeres (Neuaufstellungen) Anl. 1 zu T. A. 737/32 T2 III B v. 7. 11. 1932 entnommen. BA-MA RH 15/v. 49. Vgl. auch Anm. 38.

94 Nicht wiedergegeben. Näheres s. Anm. 116.

95 Nicht wiedergegeben; auf 20 Doppelseiten, bis zur Einheitsebene differenzierte Aufstellungs- und Dislokationsanweisungen. Aufgeschlüsselt nach Wehrkreisen und Standorten. BA-MA RH 15/34.

96 In Ubersichts- und Dislokationsskizze gem. AnI. 2 (nicht wiedergegeben) für WK IV Dresden Unterbringungsräume für nur 2 Div. vorgesehen. Neue 3. Div. in Magdeburg.

97 RWM Nr. 892/33 gKdos V2 Vb v. 29. 12. 1933 - Weisung mit Ausführungsbestimmungen zur Meldung "Kosten für die Unterbringung der Neuaufstellungen 1934-1935 « BA-MA RH 15/34.

98 Die Ziffer 4a-f dieses Dokumentes ist mit den Ausführungen des Chefs. T. A. am 20./21. 12. 1933, Dok. 3, „Unterbringung im einzelnen « identisch. Vgl. auch Anm. 158.

99 Die Rückhaltzone wurde durch die Festungsbauten der Landesbefestigung markiert. Im Osten z. B. "Pommernstellung «, "Festungsfront Oder-Warthe-Bogen«, „Oderstellung«. Mueller-Hillebrand, S. 41.

${ }^{100}$ Der Terminus ist dem Plan v. 7. 11. 1932 entlehnt. "Die kurzdienenden Ergänzungsmannschaften (Miliz) bilden einen Teil des aktiven Heeres, für den aus Notstandsgründen (finanzielle und politische Lage) die aktive Dienstzeit auf eine 3monatige Ausbildung und 4-5 kurz bemessene Reserveübungen herabgesetzt ist. «Denkschrift betreffend Ausbildung des Ergänzungsbedarfs des A-Heeres. BA-MA 15/v. 49.

101 Vgl. die Ausführungen Chef T. A., Dok. 3, "Unterbringung im einzelnen«, Ziff. 5.

102 Die Heeresstandortverwaltungen waren zusammen mit den Heeresstandortkassen und den nachgeordneten Heeresstandortverwaltungszweigstellen direkt dem Wehrkreis unterstellte Behörden.

${ }^{103}$ Zur Geschichte des Heeresbauwesens, einschließlich Literaturhinweise, s. Absolon II, S. $106 f$. 
104 Ebd., S. $104 f$.

$105 \mathrm{Vgl}$. Anm. 158 „Unterbringung im einzelnen (Dok. 3) Ausführungen Chef T. A.

106 Material für WK VII (München) BA-MA RH 53-7/1085, 1086.

$107 \mathrm{Vgl}$. die Ausführungen Chef T. A., Dok. 3, Ziff. 4, „Geheimhaltung und Tarnung ; s. auch Anm. 166. In den nachfolgenden Tarnbezeichnungen ist schw.F.H.Battr. in schwere Feldhaubitzbatterie aufzulösen.

$108 \mathrm{Vgl}$. Anm. 166, 167.

109 Deckblatt verschollen; ohne Herausgabestelle und Registraturnummer; handschriftliche Vermerke in Rot: I. Teil; in Blau: 21c IIa gKdos W. 22. 12. 33; keine Paraphen; Ordnungsziffer der Ablage im WK VII -30-. Das Dokument ist in fünf Teilen erhalten, maschinengeschrieben, mit zwei Typen. Teil I, IV, V mit Maschine A); Teil II, III mit Maschine B). Die Datierung der Besprechung - einmal im RWM, ein andermal in Berlin - ist nicht ganz eindeutig. Eindeutig als Haupttitel ist dem fünfteiligen Dokument "Besprechung in Berlin am 21. und 22. 12. 1933 * vorangeschickt. Die Teile II, III, IV vermerken den 20. und 21. Dezember als Besprechungstage; der Teil V ist ohne diese Datumsangabe erhalten. Für die Teile II-IV ist München als Ort der Niederschrift des Protokolls angegeben. Lediglich Teil I vermerkt Berlin. Die Teile IV und V sind in München am 22. 12. 1933 gefertigt. Da der 21./22. 12. nur einmal allerdings als Haupttitel - dreimal jedoch der 20./21. bestimmt wurde und München als Ort der Niederschrift genannt ist, mag eine (ungewollte?) Vordatierung erfolgt sein. Ich neige dazu, die Besprechung auf Mittwoch/Donnerstag, den 20./21. 12. 1933 in Berlin zu datieren. Die Protokollierung erfolgte dann in München unmittelbar nach der Rückreise der Offiziere des WK VII in München am Freitag, dem 22. 12. 1933. Am Sonnabend, dem 23. 12., unmittelbar vor Weihnachten, wären Rückreise von Berlin und Protokollierung in München ohne Not schwer vertretbar gewesen. Zahlreiche Schreib- und Tippfehler, Verbesserungen und handschriftliche Hinzufügungen deuten den Zeitdruck an, unter dem die Protokolle angefertigt wurden.

110 Auch während des Jahres 1934 rissen die Gespräche über den Abschluß einer Konvention nicht ab. Noch am 5. 8. 1934 erklärte Gen v. Reichenau in einem Interview mit ausländischen Pressevertretern, Deutschland sei noch immer bereit, eine Rüstungskonvention abzuschließen. Erst mit dem 16. 3.1935 war der Abschluß einer Konvention deutscherseits kein Verhandlungsziel mehr.

111 Besprechung v. 10. 11. 1933 über "Maßnahmen zum Schutz der nationalen Sicherheit des Reiches (Spionage-Abwehr) « zwischen dem R WM und allen übrigen Reichsministerien. Grundlage der Besprechung: Erlaß Reichsverteidigungsminister Abw. Nr. 496/33 III L gKdos v. 3. 11. 1933. Darin "schärfste Zusammenfassung aller im Abwehrkampf gegen Spionage und Verrat eingesetzten Kräfte«. Forderung: "einheitlich geführte Kampffront «. BA-MA RH 15/34. Auch während des Jahres 1934 ständige Appelle an die Truppe, auf die Einhaltung der Geheimhaltungsbestimmungen zu achten. Das T. A. erläuterte auch die Gründe: "Der Führer und Reichskanzler hat angeordnet, daß die Umrüstungsmaßnahmen des Heeres aus außenpolitischen Gründen unter weitgehender Tarnung durchzuführen sind. * T. A. Nr. 4914/34 gKdos T2 IIa v. 1. 9. 1934 BA-MA WK VII/2185.

112 Gemeint sind wohl die geheimen Rüstungspläne, der Umbauplan des Friedensheeres v. 7. 11. 1932 als auch die organisatorischen Vorarbeiten, die den Rahmen eines größeren Heeres bereits zu Zeiten der Weimarer Republik vorkonzipiert hatten. Indirekt kennzeichnete der Reichswehrminister sie aber auch als Improvisation.

113 "Nur « einjährige Dienstzeit auch im Hinblick auf eines der Primärziele: Beseitigung der Wehrlosigkeit und Schaffung personeller Reserven. Am 21: 12.1933 trat das »Gesetz über die Dauer der Dienstverpflichtung in der Wehrmacht « in Kraft, wurde aber nicht veröffentlicht. Das Gesetz bildete die Rechtsgrundlage für alle Anordnungen, die über die Dienstzeit der seit dem 1. 4.1933 eingestellten Soldaten erlassen wurden. Betroffen davon waren die am 1. 4. 1933 eingestellten und nach Ablauf ihrer $1 \% 2$ jährigen Dienstzeit zum 30. 9. 1934 ausscheidenden Soldaten; ihnen gebührte bei Bewerbung um Beschäftigung im öffentlichen Dienst Vorrang. Material BA-MA 15/v. 7.

$114 \mathrm{Vgl}$. Anm. 64. Der Chef des T. A. präzisierte das Ziel: "Möglichst im nächsten Sommer «.

115 Wehrgau: Ursprünglich Aufstellungsraum für eine Div. des 21 Div.-A-Heeres (Kriegsheer). Die 7 Wehrkreise hatten je drei Wehrgauleitungen aufzustellen. Befehl zur Aufstellung von Wehrgauleitungen: Chef HL T. A. Nr. 350/33 T2 III B/I b v. 27. 4. 1933 in enger Anlehnung an den Umbauplan des Friedensheeres v. 7. 11. 1932 (BA-MA RH 15/v. 28). Die Aufstellung sollte bis zum 1. 10. 1933 abgeschlossen sein und aus außenpolitischen Gründen nicht in Erscheinung treten. Die bisherigen Territorialbefehlshaber und Chefs anderer Heeresdienststellen sollten bis zur Ernennung von Wehrgaubefehlshabern deren Aufgaben ad interim wahrnehmen. Die Befehlshaber im Wehrkreis hatten ab 1. 4. 1934 die Bezeichnung Kommandierender General des WK . . . zu führen. (Korps-Bereich). Die Wehrgauleitungen -A.-Div.-Bereiche - korrespondierten mit den Zivilbehörden auf der Ebene der Oberpräsidenten bzw. Regierungspräsidenten der Länderregierungen. Wenn der Aufstellungsbefehl v. 27. 4. 1933 noch die mendgültige Neugliederung der Ersatzorganisation « zum Ziel hatte, deuten Blombergs Ausführungen jetzt darauf hin, die Strukturen der E.-Organisation den aufzustellenden Friedensdivisionen zugrunde zu legen. Mit dem Befehl zur Schaffung des 21 Div.-Friedensheeres wurden aus Aufstellungsräumen für das A-Heer Unterbringungsräume für das Friedensheer.

Aufgaben einer Wehrgauleitung: „Vorbereitung und Durchführung der Aufstellung aller auf den Wehrgau entfallenden Einheiten des A.Heeres. «

116 Nach 1919 aus den Ortswehren hervorgegangen; sollte nach den Vorstellungen der HL am 1. 4. 1933 einen neuen personellen und organisatorischen Rahmen erhalten. 34 Grz Sch Verbände mit 102 verstärkten GrzSchInfRgtern. Im A.-Fall konnten theoretisch 90000 Mann als ortsgebundene Miliz aufgeboten 
werden. Ausbildungsstand und materielle Ausstattung gaben dieser Zahl allerdings ein geringeres Gewicht. Schwerpunkt lag im Osten. In den WK I und III sollten 20 der 34 Verbände aufgestellt werden. Ab 1. 4. 1933 lief die Ausbildung der GrzSchVerbände durch das Reichsheer an. Binnen kurzer Zeit waren fast 60\% der jungen Truppenoffiziere mit der Ausbildung von Grenzschutzmännern beschäftigt. Der Reichswehrminister stellte auf einer Befehlshaberbesprechung in Bad Wildungen am 1. 6. 1933 fest, daß die Truppe weitgehend außerhalb des Heeres gebunden sei. Für die Reichswehrführung kam es bei dem jetzt neu gesteckten Aufstellungsziel vordringlich darauf an, die verzettelten Kräfte auf eigene Aufbauvorhaben zu konzentrieren. Der Zuwachs an militärischer Kampfkraft war gering. Noch im April 1934 urteilte Gen Adam, Befehlshaber im WK VII: „Dem Grenzschutz . . . kann bei dem derzeitigen Stand der Ausbildung und Ausrüstung im günstigsten Fall örtliche Bedeutung beigemessen werden. * (Wkdo VII Nr. $04141 \mathrm{gKdos} \mathrm{IB} \mathrm{v.} \mathrm{29.} \mathrm{11.} \mathrm{1934,} \mathrm{BA-MA} \mathrm{WK} \mathrm{VII/182).} \mathrm{Grundlegender} \mathrm{Erlaß} \mathrm{für} \mathrm{die}$ Ausbildung im Grenzschutz für die Zeit v. 31. 3. 1934-1. 4. 1935: Chef HL T. A. Nr. 100/34 gKdos T4 IIIa v. 5. 3. 1934. BA-MA WK VII/647. Umfangreiches Material: BA-MA WK VII/182, 647, 1453, 4082, II $\mathrm{H} 645 / 2$, II H/290.

117 Die Reibungsverluste 1933/34 im Konflikt um das *Waffenträgermonopol « gingen zu Lasten eines organisationstechnisch viel früher möglichen, vor allem aber ruhigeren Ablaufs des Heeresaufbaus. Noch immer grundlegend Bracher, Sauer, Schulz, S. 685ff. u. $897 \mathrm{ff}$.; Müller: Das Heer und Hitler, S. 88ff.; Ch. Bloch: Die SA und die Krise des NS-Regimes 1934. Frankfurt/M. 1970. Vgl. auch Anm. 23.

118 Anfänge der vormilitärischen Ausbildung fallen ins Jahr 1932. Mit der Weisung Chef HL T. A. Nr. 570/33 gKdos T2 III v. 25. 7. 1932 (BA-MA Wi F 5/498) stellte die Heeresleitung 50 Offz. für ein Vierteljahr "urlaubsweise « zur Vorbereitung einer staatlichen Wehrsportorganisation ab. Leiter und gleichzeitig Geschäftsführer des Reichskuratoriums für die Jugendertüchtigung war Gen a. D. Edwin v. Stülpnagel. Die Organisation war dem Innenressort unterstellt. Nach dern 30. 1. 1933 versuchte Blomberg die Verantwortung für die vormilitärische Ausbildung einem neuzubildenden »Reichsministerium für die deutsche Jugend « zu übertragen. (Studie RWM Nr. 1630/33 W. V. v. 18. 3. 1933. BA-MA RM 1/v. 13). Das RWM hätte sich durch den Vorbehalt einer Weisungsbefugnis für alle Maßnahmen der Landesverteidigung einen erheblichen Einfluß auf dieses Ministerium gesichert. Mit dem Kompromiß, den Blomberg hier ankündigte, verzichtete die Reichswehr auf ihren Einfluß auf die vormilitärische Ausbildung, die in Zukunft allein Sache der SA wurde. Vgl. auch Messerschmidt: Die Wehrmacht im NS-Staat, S. 112ff.; Absolon I., S. $110 \mathrm{ff}$.; Regelung der vormilitärischen Ausbildung zwischen Reichswehr und SA (Chef Ausbildungswesen v. 23. 2. 1934 in Ursachen und Folgen, Bd 10, Dok. 2367, S. 135).

119 Die Spannungen zwischen Reichswehr und SA traten im WK VII besonders deutlich zutage. Am 31. 10. 1933 warnte der Artillerieführer im WK VII in einem Schreiben an sämtliche Meldeämter: „Den SAFührern muß klar gemacht werden, daß die Einbeziehung ihrer Verbände in unsere Wehrarbeit eine ernste und verantwortungsvolle Mitarbeit ihrerseits erfordert, die von der üblichen vereinsmäßigen Arbeit in den Verbänden erheblich abweicht. « Aus der Truppe war über ständige Reibereien mit der SA berichtet worden. BA-MA WK VII/1295.

Einzelheiten und kritische Reflexionen zum Verhältnis SA - Reichswehr aus der Sicht der Betroffenen bei H. Meier-Welcker: Aus dem Briefwechsel zweier junger Offiziere des Reichsheeres 1930-1938. In: . MGM 14 (1973) 57-100 (vor allem die Briefe v. 9. 12. 1933, 14. 1. 1934) - zit. Meier-Welcker.

Beispiele von Konflikten zwischen Reichswehroffizieren und SA-Führern und die Art wie sie gelöst wurden, wurden auf der Kommandeurbesprechung am 15. u. 18. 1. 1934 in Stuttgart und Kassel bekanntgegeben.

Liebmann-Notizen (IfZ 167/51).

120 Laufbahn der Offz. -Anwärter künftig 2 Jahre. Vgl. die Ausführungen des Inspekteurs der In 1, S.124. Ab 1936 werden jährlich 2000 Offiziere von den Kriegsschulen erwartet. Befehlshaberbesprechung am 15. u. 18. 1. 1934 in Stuttgart und Kassel. Liebmann-Notizen (IfZ 167/51). Weiterführende Literatur bei Absolon II, S. 45.

$121 \mathrm{Vgl}$. die Ausführungen Chef PA.

Dazu Blomberg selbst in Einzelheiten: „Die Forderung des Abituriums für Junker war nach dem Kriege als Sparmaßnahme nicht zu umgehen. Die Forderung hat aber das Offizierkorps nicht verbessert. Eine Fülle gut geeigneten soldatischen Materials ist dadurch dem Heer verloren gegangen. Die Forderung soll daher probeweise fallengelassen werden. Offiziersanwärter ohne Abitur müssen zunächst ohne jeden Vorbehalt 1 Jahr dienen. Nach Abschluß entscheiden Vorgesetzte über Geeignetheit zum Junker. « (Befehlshaberbesprechung v. 2. u. 3. 2. 1934, Liebmann-Notizen (IfZ 167/51). Solche und ähnliche Verfuigungen lagen ganz auf der Linie, das alte Heer mit dem "neuen $*$ Staat zu versöhnen. Soziologisch bedeuten diese offenen Demokratisierungsbemühungen im Ansatz die Aufgabe des alten Prinzips der Selbstrekrutierung aus den bis dahin das Heer tragenden Schichten. Hierzu auch Bracher, Saver, Schulz, S. 918.

122 Das Reservoir der Jahrgänge 1894-1900, die Truppenoffiziere der Dienstgrade Lt bis Hptm im Weltkrieg, sollte ausgeschöpft werden. L.-Offz. waren verabschiedete Offz., die im Angestelltenverhältnis im RWM, in Stäben oder anderen Dienststellen außerhalb des Ministeriums beschäftigt wurden. 1933 wurde das L.-Offz.-Korps ausgebaut und am 16. 3. 1935 in die Wehrmacht überführt, nachdem es zuvor nach qualitativen Gesichtspunkten ausgekämmt worden war. Bei den Wiedereinstellern der SA handelte es sich um L.-Offz., die zwischenzeitlich in Führerpositionen eingerückt waren. Generelle Politik der Reichswehr war es, die Ubernahme von L.-Offz. so gering wie möglich zu halten und auch 
dann nur jüngere Offz. zu übernehmen.

Gesamtumfang zu diesem Zeitpunkt $=2000$. Im Zuge des beschleunigten Heeresaufbaues wurde der Stellenplan für die L.-Offz. im Herbst 1934 auf 3000 erweitert; Gen Beck in einer Notiz v. 2. 10. 1934. BA-MA RH 15/35. Der Stellenplan für das L. -Offz. Korps war im X-Haushalt verankert. Einzelheiten bei Absolon II, S. 57f.

${ }^{123}$ Bereits am 10. 1. 1934 erging für die Jahre 1934/35 Befehl: „Einmalige Úbernahme von aktiven Unteroffizieren in das Offizierkorps. « Pl (W) gKdos PA Nr. 30/34 IV F PA (1) W (BA-MA RH 15/34). Die 7 Inf.Div. konnten etwa 50 Uffze., die 3 Kav.Div. je 15 Uffze. vorschlagen. Insgesamt wurden 400 Uffze. vorgeschlagen und übernommen. Mueller-Hillebrand, S. 30, vermerkt, daß etwa 1500 Uffze. in das Offz.-Korps übernommen wurden. Diese Zahl bezieht sich auf die Jahre 1933-1939, erscheint aber trotzdem als zu hoch.

$124 \mathrm{Vgl}$. die A'usführung Chef T. IV.

Der Termin wurde auf der Befehlshaberbesprechung am 15. u. 18. 1. 1934 in Stuttgart u. Kassel noch einmal ausdrücklich bestätigt und unterstreicht den Willen der Reichswehrführung, die bei vielfältigen Sonderaufgaben außerhalb des Heeres zersplitterten Kräfte des Heeres für die am 1. 4. 1934 beginnende „Wehrreform « zu konzentrieren, zum anderen die Reibungsflächen mit der SA zu verringern, die hauptsächlich im Grenzschutz-Ost und den selbständigen Mobilmachungsvorbereitungen der SA auftraten. Ganz konnte sich die Reichswehr nicht durchsetzen, denn solange der Konflikt mit der SA schwelte, blieben die Lehrtrupps zum Grenzschutz-Ost kommandiert. Vgl. die Anm. 117, 118, 119.

125 Wenige Wochen später schrieb der Reichswehrminister v. Blomberg an Röhm einen Brief in dieser Frage: Inhalt: „Verleihung von SA-Dienstgraden an Wehrmacht (sei) nur da am Platz, wo Offiziere und Unteroffiziere aus Tarnungsgründen ihre Tätigkeit in SA-Uniform ausüben müssen. In anderen Fällen bäte er davon abzusehen. Wo Verleihungen vorgenommen werden, wird Mitteilung an RWM durch SA-Führung erbeten * (Befehlshaberbesprechung am 2. 2. 1934; Liebmann-Notizen (IfZ 167/51).

126 Zum Problem und zur Praxis des Arier-Paragraphen, s. Messerschmidt: Die Wehrmacht im NS-Staat. Betroffen waren im Heer 56 Offz., Uffz. u. Mannschaften.

Blomberg knüpft mit diesem Hinweis an seine Ausführungen vor den Befehlshabern in Bad Wildungen am 1. 6. 1933 an. Dort hatte er bereits die Richtung gewiesen: $»$ Arierparagraph im Beamtengesetz gilt zwar nicht für Soldaten. Daran vorübergehen können wir aber nicht. Vor allem in zwei Richtungen. Heirat und Auswahl der Fahnenjunker. "

Vor dem gleichen Kreis präzisierte Blomberg am 2. 2./3. 2. 1934 seine Haltung: "Als im Anfang des neuen Staates das Ariergesetz beraten wurde, wurde Wehrmacht stillschweigend herausgelassen. Anpassung an das Gesetz, soweit Heiraten und Neueinstellung in Frage kommt, hat Minister aus eigenem Antrieb verfügt. Es ist aber festzustellen, daß das Herauslassen der Wehrmacht aus dern Gesetz in der Praxis abträgliche Folgen gehabt hat. Es ist vorgekommen, daß Persönlichkeiten, die aufgrund des Arierparagraphen aus anderen Behörden entfernt werden mußten, der Wehrmacht zur Unterbringung mit der Begründung angeboten worden sind, Wehrmacht wäre Institution, die auf Abstammung keine Rücksicht zu nehmen brauche. "Liebmann-Notizen (IfZ 167/51). Siehe auch Absolon I, S. 154-157.

127 Seir dem 1. 10. 1933 war GenLt Beck Chef des T. A. Sein Vorgänger, GenLt Adam, wurde Befehlshaber im WK VII.

128 Vgl. Anm. 111.

129 Grundlegend neuerdings Geyer: Das Zweite Rüstungsprogramm, S. 125ff. Aufgrund einer Weisung Chef T. A. Nr. 244/34 gKdos T1 I v. 15. 2. 1934 hielt GenMaj Liese, der Chef des H.Wa. A., vor den Befehlshabern in Bad Nauheim Anfang Mai 1934 einen Vortrag "Die Rüstungslage Deutschlands, wie sie sich im Falle eines Krieges darstellt. « Die Bedeutung dieser groß angelegten Studie wird dadurch unterstrichen, daß sowohl Hitler als auch Röhm ein Exemplar erhielten. Die Rüstungslage stellte sich katastrophal dar. Eine Wehrmacht, die nach 6-8 Wochen aus gänzlichem Mangel an Munition und Sprit die Waffen strecken muß, wist weder ein brauchbares Instrument in der Hand des Feldherren noch ein Machtfaktor in der Hand des Staatsmannes, der die Außenpolitik führen will. So wird auch in Zukunft die Frage offensiver oder defensiver Operations- und Kampfführung, die Berechnung der Widerstandsfähigkeit an sich und die Zielsetzung der Außenpolitik auf Gedeih und Verderb mit der Rüstungslage verbunden sein. « Liese zog daraus den Schluß: „Grundlegende Wandlung der wehrpolitischen Lage im Westen. Außenpolitik muß Aufbauphase sicherstellen und entsprechende Bündnispolitik (sic) betreiben. « Fundstelle der Denkschrift s. Anm. 55.

130 Ende 1933 vorhanden: Gruppenkommando 1 Berlin, 2 in Kassel. Bei Kriegsausbruch 1939 waren 6 Heeresgruppenkommandos vorhanden. Näheres bei F. Frhr. v. Siegler: Die Höheren Dienststellen der Deutschen Wehrmacht 1933-1945. München 1953; Mueller-Hillebrand, S. 132; Tessin, S. 227.

131 Die Reichswehr kannte keine Armee-Korps (Generalkommandos). Bei Kriegsausbruch vorhanden: 22 Armee-Korps (Generalkommandos) einschließlich Grenztruppen.

1321939 friedensmäßig vorhanden: 35 Inf.Div.; dazu 4 Inf.Div. (mot.); 3 Geb.Div.; 5 Pz.Div.; 4 le. Div. Insgesamt: 51 Div.-Kommandos.

133 Das Friedensheer verfügte 1939 über keine Kav.Div. mehr. Aus den Stämmen der Kav.Div. waren 5 Pz.Div. aufgestellt worden.

134 Bestand 1939 noch (wieder). Zur Entwicklung der Brigade-Stäbe s. Tessin, S. 232-234.

1351939 friedensmäßig vorhanden: 4 le. Div.

1361939 friedensmäßig vorhanden: 5 Pz.Div.

137 Ein Gruppenkommando 3, München, wurde nie aufgestellt. Im April 1935 erfolgte die Aufstellung des Gruppenkommandos 3 in Dresden. 
Das Planziel der Division (1933) entsprach im wesentlichen dem Grundtyp der Inf.Div. der 1. Welle 1939 (aktives Friedensheer). Die Stärken der Inf.Rgter. wurden erhöht; zur Kriegsgliederung traten eine Aufklärungsabteilung, Nachschub-, Verwaltungs- und Sanitätsdienste hinzu. Vgl. Anm. 59 und Dok. 1 , Anl. 8.

Unter den folgenden Abkürzungen sind aufzulösen: schw.A.A. = schwere Artillerieabteilung; Kw Abw.A.A. = Kampfwagenabwehrartillerie-Abteilung; s.A.R. = schweres Artillerie-Regiment; A. A. = Aufklärungs-Abteilung.

$138 \mathrm{Vgl}$. Dok. 1, Anl. 8.

139 Erlaß mit Ausführungsbestimmungen bereits am 20. 12. 1933. RWM Nr. 750/33 gKdos Wehr A/Allg. III a (Fromm). Der Erlaß weist auf "Sammelhefte" hin, in denen die Übungsstärken für die einzelnen Truppengattungen enthalten sind. Nicht mehr auffindbar. BA-MA 53-7/1086. Sonderverteiler.

140 Einzelheiten s. Anm. 59, 137.

141 Im April 1931 unternahm das Reichsheer (RH) einen ersten nach zentralen Richtlinien gesteuerten Ausbildungsversuch mit Freiwilligen - im ganzen Reich - zur Schaffung ausgebildeter Reserven. Die Versuche verliefen positiv, sie ergaben, daß nach 7 tägiger Ausbildung eine Truppe »bedingt einsatzfähig ", nach 14 Tagen »bedingt gefechtsverwendungsfähig* war. Das waren im Grunde Notmaßnahmen; sie verstießen gegen die Bestimmungen des VV; ihr eigentliches Ziel, die Schaffung von Reserven, erreichten sie nichr. Nebenziele dominierten: Erhaltung des Wehrwillens. Chef HL; Gen v. Hammerstein, konstatierte im Nov. 1932: „Die Gefahr, daß das Heer ein Fremdkörper der Nation wird, ist beseitigt. * Allerdings beurteilte die HL die gesamte »Ausbildung außerhalb des Reichsheeres « in ihrem militärischen Wert sehr skeptisch. $»$ Die Kriegsverbände (werden im) besten Fall etwa so aussehen, wie die kurz ausgebildeten Versuchstruppenteile. Wahrscheinlich werden sie schlechter sein. \& Sie konnten Verteidigungsgefechte und gut vorbereitete kurze Angriffsgefechte in kleinem Rahmen durchführen und einmalige Märsche bis $25 \mathrm{~km}$ zurücklegen.

Material: Chef HL T. A. Nr. 628/34 T4 Ia gKdos "Z«v. 17. 9. 1931 Ergebnis der Kurzausbildungsversuche 1931; BA-MA Wi I F 5/498.

Denkschrift betr. Ausbildung des Ergänzungsbedarfs des A-Heeres v. 7. 11. 1932; HL T2 IIIB zu HL T2 Nr. 737/32 gKdos; BA-MA RH 15/v. 49.

142 Die Formulierung »22 000 Mann (der größere Teil der am 1. 4. 33 Eingestellten)« läßt m. E. zwei Deutungen zu: a) 22000 Mann, das ist der größere Teil . . . b) 22000 Mann davon der größere Teil . . . In der Literatur ist bislang unwidersprochen die Zahl von ca. 15000 zusätzlicher Neueinstellungen überliefert, so daß von der Lesart: „22 000 Mann davon (der größere Teil der am 1. 4. 33 Eingestellten) « ausgegangen werden muß. Die Restsumme zwischen 15000 und 22000 machen dann Neueinstellungen zum 1. 10. 1933 aus.

143 Allgemein waren die materiellen und personellen Rüstungsprogramme der Zwischenkriegszeit mittelfristig auf vier Jahre angelegt.

144 Dagegen die Praxis: „Alle Dienststellen und Personen müssen voribergehend auf dem Gebiete der Unterbringung sich in ihren Ansprüchen auf das äußerste beschränken. Volle Erfüllung der nach den Bestimmungen zuständigen Raumgebühr ist ausgeschlossen. « RWM Nr. 892/33 gKdos V 2 VB v. 29. 12. 1933. BA-MA RH 15/34. Vgl, auch Anm. 214.

145 Material für WK VII in BA-MA 53-7/v. 1086, 1885.

146 Die Terminologie ist nicht einheitlich. Gen Beck (Dok. 1) spricht einmal von »Allgemeine(r) Dienstpflicht ", ein andermal von "Reichsdienstpflicht". Mit beiden Begriffen wurde im internen Sprachgebrauch die Phase zwischen dem Berufsheer nach den Bestimmungen des VV und der Einführung der Allgemeinen Wehrpflicht (16. 3. 1935) bezeichnet. Man könnte auch von verdeckter Wehrpflicht sprechen. De facto bestand für die Reichswehr am Ende des Jahres 1933 in Ausbildung, Unterbringung und Versorgung die Allgemeine Wehrpflicht, wenn auch die Dienstpflichtigen zunächst über Wehrdienst oder Arbeitsdienst zu entscheiden hatten.

${ }^{147}$ Die Vorstellung ist bemerkenswert. Sie tauchte in den späteren Befehlshaberbesprechungen des Jahres 1934 nicht mehr auf. Die wehrpolitischen Wünsche des RWM eilten den außenpolitischen Möglichkeiten zunächst noch voraus. Schon im Oktober 1933 anläßlich des Austritts aus dem Völkerbund beklagte Gen Beck, daß Hitler seine Rüstungsforderungen nicht gleich mit auf den Tisch gelegt hatte. Es ging dem Chef des T. A. vordringlich darum, den Heeresaufbau aus der funktionalen Verklammerung mit der äußeren Politik zu lösen, um Ruhe für den Aufbau des Heeres zu gewinnen. Denkschrift Beck v. 20. 5. 1934 , BA-MA N 28/1.

${ }^{148}$ Die HL wies am 3. 1. 1934 alle unterstellten milit. Behörden in "Aufbau und Gliederung des freiwilligen Arbeitseinsatzes « ein. Chef HL T. A. Nr. $1 / 34$ gKdos T2 III B. BA-MA RH 15/34. Die „Freiwilligkeit * bezog sich nur auf die Wahl Wehrmacht oder Arbeitsdienst. Der freiwillige Arbeitsdienst wurde mit der Uberleitungsverordnung v. 3. 7. 1934 der Zuständigkeit des Reichsarbeitsministeriums entzogen und dem neugeschaffenen »Reichskommissar für den freiwilligen Arbeitsdienst«, Reichsarbeitsführer Hierl, unterstellt

149 Die Eckjahre wurden im Wehrgesetz v. 21. 5. 1935 beibehalten, die Pflichtzeiten für den Wehrdienst im Beurlaubtenstande heraufgesetzt. Das Wehrgesetz unterschied nur noch Reserve, Ersatzreserve, Landwehr. Text bei Absolon III, S. 345-378.

150 Regelung erfolgte durch T. A. Nr. $4119 / 34$ gKdos T2 II v. 5. 2. 1934. Künftige Grenze zwischen WK VII und WK V verlief durch Reg.Bez. Unterfranken. Vollständiger Gebietsverlust Unterfranken konnte vermieden werden. Grund: Bevölkerungsverlust; Trp.-Ub.-Platz Hammelburg sollte im 
WK VII verbleiben. T.A. entsprach dem Vorschlag Wehrkreiskommando (WKK) VII Nr. 1324/gKdos/Ib N v. 18. 1. 1934. BA-MA 53-7/1086.

151 Regelung vorgezogen auf den 1. 7. 1934. „Die Wehrgaubefehlshaber erhalten ab 1. 7. 1934 für die Inf. ihres Bereiches die Befugnisse von Kav.Div.Kdeuren«, d.h. ohne "Befugnisse in Verwaltungsangelegenheiten «. Richtlinien für die Durchführung des Heeresumbaues 1934, v. 25. 6. 1934. BA-MA WK VII/383/3459 L. Vgl, auch Anm. 116.

152 Wehrkreiskommando-Stäbe als Korpskommandos. Vgl. auch Anl. 8.

${ }^{153}$ Gemeint war die Zentralisierungs- und Gleichschaltungspolitik, mit der die neue Reichsführung in die Länderhoheit eingriff und die Eigenständigkeit der Länder weitgehend zerschlug. Gesetzliche Eingriffe: Vorläufiges Gesetz zur Gleichschaltung der Länder v. 31. 3. 1933; Zweites Gesetz zur Gleichschaltung der Länder mit dem Reich (Reichsstatthal tergesetz) v. 7. 4. 1933; Gesetz über den Neuaufbau des Reiches v. 30. 1. 1934. Erschöpfende Analyse und Darstellung bei Bracher, Sauer, Schulz, T.1, Kap. II, 4; T. 1, Kap. III,1; T. 2, Kap. I, B, 2; T. 2, Kap. IV, 3. Aus der Sicht des Reichsministeriums schienen die "veränderten Verhältnisse" vor allem bürokratische Vorteile zu bringen.

154 Die Reichsreform war gem. Art. 18 der Weimarer Verfassung ein Verfassungsauftrag, der jedoch in den Anfängen steckenblieb. Die Kongruenz von zentralisiertem Reichsaufbau und hierarchisch gegliedertem Militärapparat versprach gerade für eine im Aufbau befindliche Truppe verwaltungstechnische Vorteile. Rücksichten auf Länderkompetenzen brauchten in Zukunft nicht mehr genommen zu werden. Affinität im Detail zwischen Wehrmachtsführung und NS-Staat.

155 Zum Begriff "Innerdeutschland" vgl. Anm. 85.

$156 \mathrm{Vgl}$. Anm. 86.

157 Differenz zur Denkschrift v. 14. 12. 1933 (Dok. 1), darin waren 33 Felddivisionen vorgesehen.

$158 \mathrm{Vgl}$. Ziff. 4a-f, (Dok. 2). Verfügungen und Durchführungsbestimmungen BA-MA 53-7/1085, 1086.

159 Vgl. Anm. 93.

160 Vgl. Anm. 109.

161 Vgl. Dok. 1, Ziff. II.

162 Siehe Anm. 66.

163 Gemeint waren nur die in die Gesamtzahl von 76 bestehenden Inf.Btl. des aktiven Reichsheeres eingerechneten 9 Grz.Batl. und 4 Jäg.Batl. T. A. T2 Nr. 1113/33 gKdos III B. v. 14. 12. 1933, Anl. 6 "Vorschlag für den Aufbau des Friedensheeres in 4 Jahren. "

164 Grundlage war der A.-Plan aus dem Jahre 1932 für ein 21 Div.-Kriegsheer, dieser fußte auf dem ersten A.-Plan der Reichswehr: T. A. Nr. $943 / 27$ gKdos "Z $Z$ T2 III A. v. 30. 6. 1927. BA-MA RH 15/2.

165 Grenzsicherung West.

Regelung auf der Grundlage des Erlasses Chef HL T. A. Nr. 1030/33 gKdos T. 2 III A v. 3. 11.1933. BA-MA Wi I F5/675 "Die Grenzsicherung , West ، ist ohne personelle und materielle Unterstützung des Reichsheeres in erster Linie durch Einsatz aller personellen Kräfte der Polizei der Zivilbehörden mit ihrer Bewaffnung und Ausrüstung zu organisieren. "Sie umfaßte 1. Aufstellung eines verstärkten Grenzaufsichtsdienstes (VGAD), 2. Organisation eines Polizeischutzes in der demil. Zone, 3. Eingliederung des Bahn- und Postschutzes in die Grenzsicherung.

Mit der Organisation und Durchführung der Grenzsicherung West war u. a. der Reichsverteidigungsrat (R.V.R.) beauftragt. Einzelheiten: Protokoll der 5. Sitzung R.V.R. am 15. 11. 1933, BA-MA Wi/F5/701; Protokoll der 6. Sitzung R.V.R. v. 21. 3. 1934. IMT, Bd 36 (1949), Dok. 404-EC, S. $381 \mathrm{ff}$. Eine kritische Würdigung der Tätigkeit des R.V.R. im Rahmen der Vorbereitung der Reichsverteidigung steht noch aus. Die Protokolle der 1.-12. Sitzung (1933-1936) liegen dem Verfasser vor.

166 Neuerdings J. Sywottek: Mobilmachung für den totalen Krieg. Die propagandistische Vorbereitung der deutschen Bevölkerung auf den Zweiten Weltkrieg. Studien zur modernen Geschichte. Bd 18. Opladen 1976; vor allem das Kap. Friedenspropaganda und Tarnung der Aufrüstung, S. 49ff. Siehe auch Anm. 111.

167 Praxis in WK II: "Hinsichtlich der Geheimhaltung wird nochmals auf W.K.K. VI Nr. 1253 gKdos/Ib/N v. 4. 1. 1934 verwiesen. Inzwischen hat die bayerische Staatskanzlei auf Antrag des W.K.K. bereits einen Hinweis an die Presse erlassen zur Vermeidung irgendwelcher Erörterungen von Umbaumaßnahmen in den Zeitungen. Die Standortältesten haben die örtlichen Zeitungen daraufhin zu überwachen. « WKK VII Nr. 1325 gKdos/Ib/N v. 18. 1. 1934. BA-MA RH 53-7/1086; auch Pressebestellungen Sammlung Brammer, BA ZSG 101/3.

168 Steigerung der Abwehrkraft der Waffen durch Ausnutzung natürlicher Vorteile des Geländes und seine künstliche Verstärkung. Schwerpunkt der gem. VV zugelassenen Landesbefestigung lag im Osten des Reiches. Historisches Großprojekt der Landesbefestigung im Frieden des Dritten Reiches war der Westwall. Einzelheiten zum Aufbau der Landesbefestigung s. bei Mueller-Hillebrand, S. 38-44.

169 Es ist nicht ersichtlich, welche der 4 Reichsführerschulen für SA-Führer gemeint war.

170 Die Ausbildung erfolgte durch die weiterhin bestehenden Lehrtrupps für den Grenzschutz-Ost.

$171 \mathrm{Vgl}$. Anm. 119, 124.

172 Tarnbezeichnung: Meldeämter für den freiwilligen Arbeitseinsatz.

${ }^{173}$ Erst 1935 wurde das Radfahrbataillon 1 in Tilsit aus Abgaben der Inf. des WK I aufgestellt. (3 Radf. Kp. und 1 MG-Kp.) Tessin, S. 246 u. 248.

174 Die militärische Zusammenziehung und Ausbildung der kasernierten Hundertschaften der Schutzpolizei unter der Bezeichnung "Landespolizei« begann am 7. 9. 1933. Mit Erlaß v. 9. 3. 1934 übernahm Göring in seiner Eigenschaft als preußischer Ministerpräsident die oberste Leitung der Landespolizei, sie wurde auf Anordnung Hitlers am 21. 3. 1935 in das Heer überführt. Hitlers Motive und Gründe: 
"Die militärische Schwäche Deutschlands war der Anlaß, die Landespolizeien zu Aufgaben der Landesverteidigung heranzuziehen. Die außenpolitische Lage bedingte, daß der militärische Charakter der Landespolizeien und ihr Zusammenhang mit der Wehrmacht getarnt blieben. Der derzeitige Zustand, daß neben der Wehrmacht eine Art Polizeiarmee besteht, wird ein Ende finden, sobald es die Entwicklung der außenpolitischen Lage zuläßt. Es ist mein Wille, daß sodann die Landespolizeien in die Wehrmacht überführt werden. « Der Führer und Reichskanzler, Nr. 14/35 gKdos v. 31. 1. 1935, BA-MA II H 652/2. Tessin, S. 459ff. u. Absolon III, S. 31ff., berichten Einzelheiten organisationstechnischer Art, ohne Angaben von Gründen. Zu Spekulationen eines Interessenkonfliktes zwischen Himmler und Göring s. BA-MA ZSG 101/3 Sammlung Brammer, Bestellung Nr. 240-243 v. 5. 2. 1934.

$175 \mathrm{Vgl}$. Anm. 174. Von der Uberführung ins Heer waren ausgenommen: Landespolizeiinspektion West, Südwest, Süd (entmil. Zone). Aus außenpolitischen Rücksichtnahmen unterblieb eine geplante Verlegung von weiteren Teilen dieser Inspektionen in die entmil. Zone. Tessin, S. 462.

176 Aus den Zahlen der Uberführung in das Heer kann auf den Bestand geschlossen werden; mit einiger Sicherheit waren ca. 90 Landespolizeiabtlg. (Batle.) vorhanden; davon wurden 58 ins Heer und 3 in die Luftwaffe ( $L w)$ überführr; beider Landespolizei verblieben 28. Einzelheiten und zum Problem der Zahlen s. Tessin, S. 463. Absolon III, S. 32 nennt als absolute Zahl der Ubernahme 56000 Offz. und Wachtmeister.

177 Siehe Anm. 165.

178 Seit dem 1. 10. 1933 Oberst v. Schwedler. Sein Vorgänger, GenLt Frhr. v. d. Bussche-Ippenburg, war zum 30. 9. 1933 aus dem aktiven Dienst ausgeschieden.

179 Das Protokoll dieser Befehlshaberbesprechung muß als verschollen gelten. Es ist auch nicht in den Liebmann-Notizen vermerkt. Es darf angenommen werden, daß am 11. 11. 1933 als Zahl für den Offz.-Ersatz der Jahre 1934/1935 1800 angegeben wurde.

$180 \mathrm{Vgl}$. Anm. 174, 175, 176.

181 Zum Beurteilungswesen als der Grundlage der Beförderungen s. Absolon III, S. 291-303. Die direkte Folge dieses für die Truppe bestimmten Hinweises war die noch stärkere Heranziehung der dienstlichen Leistungen als Bestimmungselement für die Beförderung. Einzelheiten zur Beförderung der Offiziere des Heeres im Frieden bei Absolon III, S. 293-303.

$182 \mathrm{Vgl}$. Anm. 79, 122. Bereits im Herbst 1934 war der Stellenplan für die L.-Offz. auf 3000 Stellen erweitert worden.

183 Die L. -Offiziere wurden zur Entlastung der aktiven Stäbe mit den A. -Vorarbeiten betraut. Einzelheiten und Vorgeschichte bei Absolon I, S. 35-39; II, S. 57-58.

184 Bezugsgröße ist hier wieder das im April 1933 um ca. 15000 Mann vergrößerte 100000 Mann-Heer. Vgl. auch Anm. 80.

$185 \mathrm{Vgl}$. Anm. 123.

186 Die Zahl von 7300 Offz. setzt sich wie folgt zusammen:

3800 vorhandene Offz.

1350 Offz.-Ersatz (Fähnriche)

600 Polizei-Offiziere

1400 zu reaktivierende Offz.

150 Uffze. (erste Ernennungen).

187 Umfangreiches Material: Notizen zur Bedarfslage an Generalstabsoffizieren, BA-MA H 23/98; die personelle Entwicklung des Generalstabes aufgrund des Heeresaufbaues 1934-1939, BA-MA H 23/112. Vgl. auch H.-G. Model: Der deutsche Generalstabsoffizier. Seine Ausbildung in Reichswehr, Wehrmacht und Bundeswehr. Frankfurt/M. 1968.

${ }^{188}$ Die Inf.Div. und Kav.Div. der Reichswehr verfügten über einen Chef des Stabes. Die Divisionskommandeure der Inf.Div. waren zugleich Befehlshaber der Wehrkreise. Die Doppelfunktion von Truppenführer und Territorialbefehlshaber sollte in Zukunft fortfallen, deshalb konnte auf den Chef des Stabes verzichtet werden.

$\mathrm{Vgl}$. Gliederung und Standorte des Reichsheeres und der Reichsmarine nach dem Stande vom Herbst 1932. Berlin 1932.

189 Lehrgangsbeginn 1. 10. 1931; reguläres Ende 1. 10. 1934, Verkürzung also um 6 Monate. Vgl. Anm. 121.

190 Inspektion der Waffenschulen und der Luftwaffe im Reichswehrministerium. Die In 1 unterstand dem Chef HL und war für die geheime Luftrüstung zuständig. Inspektionschef war Oberstlt Felmy, später Gen der Flieger.

Ein Gesamtüberblick über die Offizierlaufbahnen im Heere bei Absolon III, S. 209-227.

191 Infanterie-Schule Dresden; Durchführung der Lehrgänge I und II.

192 Aufstellungsbefehl zum 1. 1. 1935; Chef HL T. A. Nr. 4962/34 gKdos/ T 2 Ila v. 22. 9.1934 (Sodenstern) als Kriegsschule; BA-MA RH 53-7/1085.

Einzelheiten zu Schulen des Heeres und Truppenübungsplätzen bei Absolon III, S. $156 \mathrm{ff}$.

193 Aufstellungsbefehl für die Kriegsschule Hannover erging zusammen mit der für die Kriegsschule München. Vgl. Anm. 192.

194 Zwischen 1921 und 1937 jeweils im März eines jeden Jahres für alle Oberleutnante durchgeführte Prüfung zur Ermittlung des Standes »der wissenschaftlichen Ausbildung der Offiziere«. Zweck: Auswahl der Offiziere für die Ausbildung als Führergehilfen (Generalstabsoffiziere). Mit Erlaß v. 23. 6. 1937 umbenannt in "Kriegsakademieprüfung". Näheres bei Absolon II, S. 39-47 - dort auch weiterführende Literatur U. III, S. 482. 
195 Amtschef seit dem 1. 10. 1933 Oberst Fromm.

196 Chef W. A. bedient sich hier der Begrifflichkeit des politischen und publizistischen Kampfes gegen das "artfremde" und "aufgezwungene» Wehrsystem des Berufsheeres. Auch in solchen Nebensächlichkeiten kommt die Teilaffinität zwischen NS-Staat und Reichswehrführung zum Ausdruck.

197 Gesetz über die Dauer der Dienstverpflichtung in der Wehrmacht v. 21. 12. 1933. Vgl. Anm. 113.

198 Federführend für die Bearbeitung der Durchführungsbestimmungen für die Versorgungsempfänger war die Abteilung für Heeresfachschulwesen und Versorgungswesen (Vers) im Allgemeinen Heeresamt. Die Ausführungsbestimmungen gingen tatsächlich erst im März der Truppe zu und betrafen die nach $1 \frac{1}{2}$ ) jähriger Dienstzeit am 30.9. 1934 ausscheidenden Soldaten der Einstellungsquote v. 1. 4. 1933.

199 Im Zuge der allgemeinen Wirtschaftsnot und durch Notverordnungen erfolgte schrittweiser Abbau der Stellen im öffentlichen Dienst. An eine Unterbringung dort konnte vorerst nicht gedacht werden. „Ende 1933 warteten noch rund 52000 Versorgungsanwärter auf ihre planmäßige Anstellung als Beamte. « Absolon II, S. 287. Arbeitsplätze konnten nur im Rahmen der Arbeitsbeschaffungspläne und durch Einwirkung auf die Wirtschaft bereitgestellt werden. Einzelheiten bei Bracher, Sauer, Schulz, S. 655-671. In den "Richtlinien für die Ausbildung außerhalb des Reichsheeres "Chef HL T.A. Nr. 816/32 gKdos T2 IIIa/T4 III v. 1. 12. 1932 klang der Gedanke bereits an. BA-MA II H/292. Als Anreiz für den freiwilligen Dienst im Grenzschutz war »bevorzugte "Berücksichtigung bei der staatlichen Heranführung zur Arbeit durch die Arbeitsämter « zugesagt. Vgl. auch die Ausführungen des Chefs der Allgemeinen Abteilung.

$200 \mathrm{Vgl}$. Anm. 199. Zur Entwicklung des milit. Fürsorge- und Versorgungswesens s. Absolon II, S. 266-288 u. III, S. 417.

201 „Bürgersteuerberechtigt gegenüber ledigen kasernierten Angehörigen der Wehrmacht ist nach der Verordnung v. 26. 1. 1934 (RGBl. I 64) für jeden Monat diejenige Gemeinde, in der sich am Ende dieses Monats die standortmäßige Unterkunft des Steuerpflichtigen befindet. Für die Höhe der Bürgersteuer ist der Steuersatz dieser Gemeinde maßgebend. Die Angehörigen der Wehrmacht sind nach $\$ 5$ Abs. 2. der Verordnung v. 17. 10. 1934 (RGBl. I 987) von der Bürgersteuer befreit. * Handbuch der neuzeitlichen Wehrwissenschaften, hrsg. im Auftrag der Deutschen Gesellschaft für Wehrpolitik und Wehrwissenschaften von H. Franke. Bd 1. Berlin, Leipzig 1936, S. 715.

202 Regelung aufgrund des Erlasses Vers. Nr. 3293/33 gKdos Ia II. Ang. v. 11. 12. 1933, betr.: Abfindung kurzdienender Soldaten. BA-MA RH 15/34.

${ }^{203}$ Marginal ohne Paraphe: "Widerspruch Karmann am 12. 1. 1934. « Oberst Karmann wurde am 1. 2. $1934 \mathrm{mit}$ der Leitung des Heeresverwaltungsamtes beauftragt und am 1. 3. 1934 Chef des Amtes.

204 Einzelheiten bei Meier-Welcker, Briefe v. 9. 12. 1933 u. 14. 1. 1934.

205 Im Vergleich des Wehrplanes v. 7. 11. 1932 und des Neuen Friedensheeres vom Dez. 1933 stellt sich die personelle Ausschöpfung eines durchschnittlichen wehrfähigen Jahrgangs von 300000 Köpfen wie folgt dar:

7. 11. 1932: ca. $28 \%=85000$ Köpfe (Ausbildung im Rahmen des Heeres)

$$
\text { ca. } 72 \%=215000 \mathrm{Köpfe} \text { (Ersatzreserve, Grenzschutz, Arbeitsdienst) }
$$

Dez. 1933: 60\% $=180000 \mathrm{Köpfe} \mathrm{(Dienstpflichtige} \mathrm{für} \mathrm{das} \mathrm{Heer)}$ $40 \%=120000 \mathrm{Köpfe}$ (Arbeitsdienst)

Also eine gute Verdoppelung der im Rahmen des Heeres auszubildenden Mannschaft.

$206 \mathrm{Vgl}$. Anm. 202. Einzelheiten zur Versorgung der kurzdienenden Soldaten gab Minister v. Blomberg am 2. 2./3. 2. 1934 bekannt. Liebmann-Notizen (IfZ 167/51).

207 Bezieht sich auf eine Dienstzeit von $1 \frac{1}{2}$ Jahren. Vgl. Anm. 202.

200 Zivilversorgungsschein mit Ubernahmeberechtigung in den öffentlichen Dienst. Siehe auch Anm. 200.

$209 \mathrm{Vgl}$. Anm. 139.

210 Am 1. 12. 1933 wurden in der neugeschaffenen Organisation des Ersatz- und Meldewesens für den freiwilligen Arbeitseinsatz »Reichswehrwerbestellen« errichtet. Tarnbezeichnung für » Wehrbezirkskommando". Erst ab 1. 11. 1934 wurde das Werbegeschäft des Friedensheeres offen betrieben. Erlaß: WKK VII Nr. 03560 gKdos/Ib/E v. 23. 10. 1934. BA-MA RH 53-7/1085.

211 Näheres zu den Heeresergänzungsbestimmungen (HEB) bei Absolon I, S. 150-152.

212 Einzelheiten und Entwicklung der Sonderlaufbahnen s. Absolon III, S. 237-241.

${ }^{213}$ Im gesamten Jahre 1933 wurden aus der Reichswehr (Heer und Marine) 550 ausgebildete Fliegeroffz. in die (geheime) Lw überführt. Siehe Völker I, S. 56. Allerdings findet sich bei Völker kein tatsächlicher Abgabeplan für die Jahre 1933-35, aufgeschlüsselt nach Offz., Uffz., Mannsch. Bei der Enttarnung der Lw betrug die Kopfzahl der Lw 1100 Offz. und 17000 Uffze./Mannsch. (Fliegertruppe und Flaktruppe). D. Irving: Die Tragödie der deutschen Luftwaffe. Frankfurt/M., Berlin, Wien 1975, S. 63 nennt ohne Beleg - für das Jahr 1933 eine Zahl von 4000 Uffze./Mannsch. Tatsächliche Abgaben an Offz. : 218 (bis 1. 10. 1933); Abgabeziel bis Jan. 1934: 70 Offz. und 1600 Uffze./Mannsch. "Ab 1. 4.1934 wirbt Luftwaffe Ersatz selbst an. « Bemerkungen Reichswehrminister auf der Befehlshaberbesprechung in Berlin am 3. 10. 1933, Liebmann-Notizen (IfZ 167/51). Nach dem 3. 10. 1933 ist der Abgaberahmen also erheblich erweitert worden.

214 RWM v. 29. 12. 1933: "Bei den nach dem neuesten Plan 1934-1935 hinzutretenden Neuaufstellungen, Verstärkungen und Verlegungen müssen zunächst die vorhandenen Kasernen in weitestem Umfange ausgenutzt werden: 4,5 qm je Mann unter Umständen noch darunter gehen (Schränke auf die Flure stellen).« Nur bei Kasernenneubauten galt die Raumgebühr von 6 qm pro Mann. Vgl. Anm. 144 
215 Deutlicher Ausdruck der sich gegenseitig überholenden personellen und materiellen Planziele, ohne daß beides in einer gemeinsamen Zielgröße konvergierte.

216 Ausrüstungsnachweis Reichsheer. (A.N.R.H.).

217 Zuweisungen aus dem Reichswehrhaushalt und anderen Ministerien.

218 "Ubliche Bezeichnung für die sbunten` oder geheimen Rüstungshaushalte. « Geyer: Das Zweite Rüstungsprogramm, S. 167 Anm. 160.

219 Chef der Ausbildungsabteilung T4 war Oberstlt Reinhardt.

$220 \mathrm{Vgl}$. Anm. 124.

${ }^{221}$ RWM am 2. 2./3. 2. 1934, Befehlshaberbesprechung, Liebmann-Notizen (IfZ 167/51). "Bildung eines Reserveoffizierkorps. Was dazu bisher an Kurzausbildung getan, ungenügender Notbehelf. Künftig kann der einjährig Dienende am Schluß des Dienstjahres die Eignung zum Reserveunteroffizier beweisen. Durch weitere UUbung(en) Eignung zum Reserveoffizier. «

222 Abkürzungen im folgenden: Ausbildungsvorschrift Infanterie, Kavallerie, Artillerie, Pioniere, Nachrichtentruppe, Kraftfahrtruppe. 
, 